\title{
Hydroxyapatite Supported Molybdenum Oxide Catalyst for Selective Oxidation of Methanol to Formaldehyde: Studies of Industrial Sized Catalyst Pellets
}

\author{
Thrane, Joachim; Mentzel, Uffe Vie; Thorhauge, Max; Høj, Martin; Jensen, Anker Degn
}

Published in:

Catalysis Science \& Technology

Link to article, DOI:

10.1039/D0CY01931C

Publication date:

2021

Document Version

Peer reviewed version

Link back to DTU Orbit

Citation (APA):

Thrane, J., Mentzel, U. V., Thorhauge, M., Høj, M., \& Jensen, A. D. (2021). Hydroxyapatite Supported Molybdenum Oxide Catalyst for Selective Oxidation of Methanol to Formaldehyde: Studies of Industrial Sized Catalyst Pellets. Catalysis Science \& Technology, 11, 970-983 . https://doi.org/10.1039/D0CY01931C

\section{General rights}

Copyright and moral rights for the publications made accessible in the public portal are retained by the authors and/or other copyright owners and it is a condition of accessing publications that users recognise and abide by the legal requirements associated with these rights.

- Users may download and print one copy of any publication from the public portal for the purpose of private study or research.

- You may not further distribute the material or use it for any profit-making activity or commercial gain

- You may freely distribute the URL identifying the publication in the public portal 


\title{
Hydroxyapatite Supported Molybdenum Oxide Catalyst for Selective Oxidation of Methanol to Formaldehyde: Studies of Industrial Sized Catalyst Pellets
}

\author{
Joachim Thrane ${ }^{1}$, Uffe Vie Mentzel ${ }^{2}$, Max Thorhauge ${ }^{2}$, Martin Høj ${ }^{1}$, Anker Degn Jensen ${ }^{1 *}$ \\ ${ }^{1}$ Department of Chemical and Biochemical Engineering, Technical University of Denmark (DTU), DK- \\ 2800 Kgs. Lyngby, Denmark. \\ ${ }^{2}$ Haldor Topsøe A/S, DK-2800 Kgs. Lyngby, Denmark. \\ *aj@kt.dtu.dk
}

\begin{abstract}
In this study, $10 \mathrm{wt} \% \mathrm{MoO}_{3}$ supported on hydroxyapatite $\left(\mathrm{HAP}, \mathrm{Ca}_{5}(\mathrm{OH})\left(\mathrm{PO}_{4}\right)_{3}\right)$ pellets were investigated as catalysts for the selective oxidation of methanol to formaldehyde. HAP was synthesized by coprecipitation and pressed to industrial sized pellets with different densities $\left(1.18 \mathrm{~g} / \mathrm{cm}^{3}-1.76 \mathrm{~g} / \mathrm{cm}^{3}\right)$ to investigate the influence of pellet density and porosity on the catalytic performance. The pellets were wet impregnated to obtain $10 \mathrm{wt} \% \mathrm{MoO}_{3}$. The catalysts were characterized by X-ray diffraction (XRD), $\mathrm{N}_{2}$ physisorption, scanning electron microscopy coupled with energy dispersive X-ray spectroscopy (SEM-EDX), inductively coupled plasma optical emission spectroscopy (ICP-OES) and Hg-porosimetry. The catalytic performance was evaluated at $250-400^{\circ} \mathrm{C}$ for up to $100 \mathrm{~h}$ continuous operation in a single pellet reactor with $300 \mathrm{NmL} / \mathrm{min}, 5$ vol.\% $\mathrm{MeOH}, 10$ vol.\% $\mathrm{O}_{2}$ in $\mathrm{N}_{2}$. The $\mathrm{MoO}_{3} / \mathrm{HAP}$ pellets lost between $10 \%$ and $23 \%$ of their initial activity while an industrial $\mathrm{MoO}_{3} / \mathrm{Fe}_{2}\left(\mathrm{MoO}_{4}\right)_{3}$ reference catalyst lost $\sim 11 \%$ within $100 \mathrm{~h}$ on stream at $350^{\circ} \mathrm{C}$. Despite the $\mathrm{MoO}_{3} / \mathrm{HAP}$ catalysts did not outperform the FeMo reference, it was still deemed of interest for further study and optimization as the difference was relatively small. Especially since the pellets weight loss due to Mo volatilization was $>70 \%$ lower compared with the FeMo catalyst within a $118.5 \mathrm{~h}$ test. A random pore model, together with overall effectiveness factor calculations for both powder and pellets were used to calculate the pellet activity from measured powder activity, providing reasonable agreement between the calculated and the observed rate constants for the pellets. An increase in both activity and selectivity to formaldehyde was obtained with decreasing pellet density, due to decreasing pore diffusion limitations of both methanol
\end{abstract}


into and formaldehyde out of the pellet. At $350^{\circ} \mathrm{C}$ the lightest (and weakest) pellet achieved an initial selectivity to formaldehyde of $87.5 \%$ at $25.1 \%$ conversion. The primary by-products were dimethoxymethane (DMM) (C based selectivity of $6 \%)$ and $\mathrm{CO}(\mathrm{C}$ based selectivity of $4.7 \%)$. The catalysts are promising for application at the front-end of an industrial formaldehyde synthesis reactor to limit the loss of $\mathrm{MoO}_{3}$ due to evaporation with accompanied rise in reactor pressure drop.

\section{Keywords}

- Formox process, selective oxidation, formaldehyde, molybdate, methanol,

\section{Abbreviations}

AHM Ammonium heptamolybdate tetrahydrate

BET Brunauer-Emmett-Teller

DME Dimethyl ether

DMM Dimethoxymethane

EDX Energy dispersive X-ray spectroscopy

ICP-OES Inductively Coupled Plasma Optical Emission Spectroscopy

$\mathrm{MeOH} \quad$ Methanol

MF Methyl Formate

SSA Specific Surface Area

XRD X-ray Diffraction 


\section{Introduction}

The global production of formaldehyde has grown to over 50 million metric tons of formalin (37-57 $\mathrm{wt} \%$ formaldehyde in water) per year with an expected consumption of 60 million tons formaldehyde per year before $2030{ }^{1}$ giving an annual market value growth rate of nearly $5 \%$ in this decade ${ }^{2}$. The demand for formaldehyde is met by primarily two industrial catalytic processes, where the Formox process (overall plant yield of $90-95 \%{ }^{3}$ ) ${ }^{4,5}$ constitutes two thirds of the annual global formaldehyde production ${ }^{6}$. The state of the art catalyst for the Formox process has for nearly seven decades been a ferric molybdate catalyst with a surplus of molybdenum oxide $\left(\mathrm{MoO}_{3} / \mathrm{Fe}_{2}\left(\mathrm{MoO}_{4}\right)_{3}\right.$, in this article called FeMo $)^{5}$. Amorphous $\mathrm{MoO}_{x}$ on the catalyst surface has been suggested to be the active phase ${ }^{7-14}$, which like the excess crystalline $\mathrm{MoO}_{3}$ forms volatile methoxy compounds, leading to a loss of Mo from the catalyst during time on stream ${ }^{15-17}$ and a lifetime of less than 1.5 years ${ }^{15}$ even with Mo/Fe ratios of 2-

$3^{15,18-20}$. The volatilized gaseous Mo species are deposited as needle shaped $\mathrm{MoO}_{3}$ crystals in the void spaces of the reactor from decomposition of the volatile molybdenum compounds when the methanol concentration and temperature decreases ${ }^{15,21}$, resulting in lower selectivity and increasing pressure drop over the reactor with time ${ }^{22}$.

Within the last 5 years, our group has worked with understanding the deactivation of the industrial FeMo catalyst as well as looked into alternative catalytic materials to improve the catalyst lifetime. The deactivation of powder FeMo catalyst was studied rigorously by activity measurements and numerous characterization techniques over $600 \mathrm{~h}$ on stream ${ }^{23-25}$. We developed a compartmental model for an industrial fixed bed reactor to investigate the influence of pellet size and $\mathrm{MoO}_{3}$ content in the inlet part of the reactor on the development of the pressure drop ${ }^{26}$ utilizing a previously made single pellet model for the loss of $\mathrm{MoO}_{3}$ from an industrial FeMo pellet ${ }^{27}$. Recent papers from other research groups dealing with understanding the industrial type catalyst includes preparation of $\mathrm{Mo} / \mathrm{Fe}=1.7$ catalyst with $\gamma$ $\mathrm{Al}_{2} \mathrm{O}_{3}$ by co-precipitation to provide information of the structure sensitivity of the reaction ${ }^{28}$, modelling of the deactivation behavior for a multi-tube industrial reactor ${ }^{29}$, new methods of preparation ${ }^{30,31}$, DFT studies of methanol partial oxidation ${ }^{32}$ and investigations of the active site ${ }^{33,34}$. A CFD study on the 
influence of pellet shape (cylinders, spheres, rings and trilobes) on reactor performance found that rings gave the best overall performance, trilobes had the lowest pressure drop and a mixture of rings and trilobes may give a slight operational improvement ${ }^{35}$.

On the development of novel catalytic materials we recently studied the alkali earth metal molybdates $\left(\mathrm{MgMoO}_{4}, \mathrm{CaMoO}_{4}, \mathrm{SrMoO}_{4} \text { and } \mathrm{BaMoO}_{4}\right)^{36}$ and $\mathrm{MoO}_{3}$ supported on hydroxyapatite and the strontium analogue as catalysts for the selective oxidation of methanol to formaldehyde, and found the apatite supported catalysts showed impressive catalytic stability ${ }^{37}$. Several studies of alternative catalytic systems for the selective oxidation of methanol to formaldehyde have been published, with some focus on molybdenum oxide ${ }^{38-47}$ and other metal oxide catalysts ${ }^{38,47-53}$, but most of it on vanadium containing catalysts, such as vanadates ${ }^{3,47,54-60}$, phosphates ${ }^{61-64}$ and vanadium oxide ${ }^{46,47,49,65-77}$. Very few of the alternative systems have been investigated as pellets. This is relevant since the size and shape of the pellets have major influence on the catalytic performance, particularly with powders showing much faster evaporation of Mo than pellets ${ }^{23,27}$.

In this work, we study our previously developed $10 \mathrm{wt} \% \mathrm{MoO}_{3} / \mathrm{HAP}$ catalyst ${ }^{37}$ in the shape of industrially sized catalyst pellets. The pellets are characterized by activity measurements for up to $100 \mathrm{~h}$, by BET, SEM, XRD, ICP and Hg-porosimetry, and a random pore model was applied to understand the influence of pellet density/porosity on the activity. The weight loss due to Mo evaporation is also measured and compared to the weight loss of FeMo pellets.

\section{Experimental}

\subsection{Catalyst Synthesis}

The synthesis of the catalysts was generally performed in three steps: co-precipitation of the apatite support, pressing the apatite powder as pellets with dimensions like the industrially used FeMo catalyst and impregnation of the pellets with ammonium heptamolybdate. However, the first pellets (\#1) were made by impregnating and calcining before pressing to pellets with similar density as the FeMo reference and then calcined again. These pellets were found highly inhomogeneous (Figure S6), making it impossible to determine if there was a volatilization front in the pellets, as observed for FeMo catalyst 
pellet by SEM ${ }^{27}$, and thus another synthesis method was needed. The \#1 pellets were still tested for activity. For the synthesis the following chemicals were used: $\mathrm{Ca}\left(\mathrm{NO}_{3}\right)_{2} \cdot 4 \mathrm{H}_{2} \mathrm{O}$ (Sigma-Aldrich, puriss. P.a., ACS reagent, 99-103\%), $\mathrm{Sr}\left(\mathrm{NO}_{3}\right)_{2}$ (Fluka, puriss. P.a. ACS; $\geq 99.0 \%(\mathrm{KT})$ ), $25 \mathrm{wt} \%$ aqueous $\mathrm{NH}_{3}$ (VWR AnalaR NORMAPUR), citric acid $\mathrm{C}_{6} \mathrm{H}_{8} \mathrm{O}_{7} \cdot \mathrm{H}_{2} \mathrm{O}$ (Sigma-Aldrich, ACS Reagent $\geq 99.0 \%$ ), $\left(\mathrm{NH}_{4}\right)_{6} \mathrm{Mo}_{7} \mathrm{O}_{24} \cdot 4 \mathrm{H}_{2} \mathrm{O}$ (Sigma-Aldrich, puriss. p.a., ACS reagent , $\geq 99.0 \%(\mathrm{~T})$ ), $\left(\mathrm{NH}_{4}\right)_{2} \mathrm{HPO}_{4}($ SigmaAldrich; BioUltra, $\geq 99.0 \%(\mathrm{~T}))$

\subsubsection{Preparation of Apatite Support}

The hydroxyapatite support was co-precipitated as described earlier ${ }^{37}$. The support was then calcined at $400^{\circ} \mathrm{C}$ for $4 \mathrm{~h}$ with a heating rate of $5^{\circ} \mathrm{C} / \mathrm{min}$ in a muffle furnace and crushed to below $250 \mu \mathrm{m}$. The hydroxyapatite was mixed with $2 \mathrm{wt} \%$ graphite and $1 \mathrm{wt} \%$ dry wax, before being pressed as pellets in a Kilian SP300 single punch tablet press mounted with a pellet matrix for cylindrical, ring-shaped pellets with $4.55 \mathrm{~mm}$ outer diameter and $1.72 \mathrm{~mm}$ in inner diameter. The filling and punching depth were varied to yield pellets with different densities and thus porosities. In total, 6 different batches of pellets (\#1 to \#6) were made, where \#1 had the highest density, and \#6 the lowest. The pellets were then calcined at $600^{\circ} \mathrm{C}$ for $4 \mathrm{~h}$ in static air with a heating rate of $5^{\circ} \mathrm{C} / \mathrm{min}$.

\subsubsection{Impregnation}

The pellets (\#2 to \#6) were impregnated with ammonium heptamolybdate (AHM, $\left.\left(\mathrm{NH}_{4}\right)_{6} \mathrm{Mo}_{7} \mathrm{O}_{24} \cdot 4 \mathrm{H}_{2} \mathrm{O}\right)$ dissolved in appropriate amounts (Table S1) in a solution of 77 vol. $\%$ water and 23 vol. $\% 30 \mathrm{wt} \% \mathrm{H}_{2} \mathrm{O}_{2}$ in $\mathrm{H}_{2} \mathrm{O}$, which increased the solubility of $\mathrm{AHM}{ }^{78}$. The water pore volume of each pellet batch was measured by submerging $0.68-0.89 \mathrm{~g}$ of dry pellets (10-16 pellets) in water for $2 \mathrm{~min}$. The water (including pellets) was poured into a perforated crucible, which was stamped into a table covered with a paper towel six times. The weight difference was used as the water pore volume. The AHM concentrations of the impregnation solutions were adjusted for each pellet batch, aiming for a nominal loading of $10 \mathrm{wt} \% \mathrm{MoO}_{3}$. The impregnations were performed by the same procedure as the water pore volume measurements with the AHM solutions instead. The pellets were dried in the fume hood at ambient conditions over several days and calcined in a muffle furnace in static air for $4 \mathrm{~h}$ at $500^{\circ} \mathrm{C}$ with a heating rate of $5^{\circ} \mathrm{C} / \mathrm{min}$. The impregnations of (\#2) were steps towards the final method used on pellets \#3-6. 
The impregnations of (\#2) were performed in two different ways: (a) by immersing overnight in an aqueous AHM solution and (b) immersing for $\sim 2$ hours in a solution of 77 vol. $\%$ water and 23 vol.\% $30 \mathrm{wt} \% \mathrm{H}_{2} \mathrm{O}_{2}$ (which increased the solubility of $\mathrm{AHM}^{78}$ ) in $\mathrm{H}_{2} \mathrm{O}$ with $\mathrm{AHM}$ for $10 \mathrm{wt} \% \mathrm{MoO}_{3}$ nominal loading. These samples are named $2 \mathrm{a}$ and $2 \mathrm{~b}$, respectively.

\subsection{Characterization}

\subsubsection{X-ray Powder Diffraction, ICP-OES and Nitrogen Physisorption}

X-ray powder diffraction, ICP-OES, and BET were performed as described previously in ${ }^{36}$. For the XRD the reference diffractograms were taken from the Inorganic Crystal Structure Database (ICSD) ${ }^{79}$ with the following collection codes for the phases: $\mathrm{CaMoO}_{4}$ (417513), hydroxyapatite (26204), $\mathrm{MoO}_{3}$ (152313), C, graphite (31170).

\subsubsection{Hg-porosimetry}

The porosity of the support pellets was measured by Hg-porosimetry on a Micromeritics Autopore IV 9520 instrument. The data were acquired while ramping the pressure from ambient to 4140 bar (covering pore radius of $17-70000 \AA$ ). The contact angle was assumed to be $140^{\circ}$. Before measurements the pellets were crushed and dried at $250^{\circ} \mathrm{C}$ for $2 \mathrm{~h}$. The measurement was performed on four pellets immediately after drying to have sufficient sample size.

\subsubsection{Scanning Electron Microscopy}

Scanning Electron Microscopy (SEM) was performed using a Zeiss Gemini microscope controlled by the Pathfinder and Smart SEM software. The pellets were cast in epoxy polymer and cut through the middle along the radial axis and polished. The pellets were covered in app. $30 \mathrm{~nm}$ of electron conducting carbon. The measurements were performed in high vacuum, with a collector bias of $300 \mathrm{~V}, \mathrm{EHT}=15$ $\mathrm{kV}$, and an ESB grid of $780 \mathrm{~V}$ with varying magnifications. Sample compositions were determined using energy dispersive X-ray spectroscopy (EDX) mapping. The maps had an image resolution of 512 by 340 pixels, and a magnification of 1142 or 1536 times. 


\subsection{Catalytic Activity and Selectivity}

Catalytic activity, selectivity and stability were measured using a lab scale, packed bed/single pellet reactor setup described in detail elsewhere ${ }^{23,80,81}$. Measurements on powder were carried out using 6/4 $\mathrm{mm}$ outer/inner diameter U-shaped quartz reactors loaded with $25 \mathrm{mg}$ of the catalyst sample in a 150$250 \mu \mathrm{m}$ sieve fraction diluted with $150 \mathrm{mg}$ of $\mathrm{SiC}$ with a feed of $150 \mathrm{NmL} / \mathrm{min}(\mathrm{NmL}=\mathrm{mL}$ at Normal conditions, $1 \mathrm{~atm}$ and $0^{\circ} \mathrm{C}$ ), 5 vol.\% $\mathrm{MeOH}, 10$ vol.\% $\mathrm{O}_{2}$ in $\mathrm{N}_{2}$. To facilitate the testing of industrial sized pellets, $7 / 5 \mathrm{~mm}$ outer/inner diameter U-shaped quartz reactors loaded with a single pellet were used. $8 / 6 \mathrm{~mm}$ outer/inner diameter quartz tubes were welded to the reactor ends to fit standard Swagelok fittings. Here a flow of $300 \mathrm{NmL} / \mathrm{min}$ was used. The activity tests, data acquisition and data treatment were conducted as described in ${ }^{36}$.

The selectivity was calculated according to Equation (1) and conversion according to Equation (2).

$$
\begin{gathered}
S_{i}=\frac{v_{i} y_{i}}{\sum_{i} v_{i} y_{i}} \\
X=\frac{\sum_{i} v_{i} y_{i}}{y_{\mathrm{CH}_{3} \mathrm{OH}}+\sum_{i} v_{i} y_{i}}
\end{gathered}
$$

Where $v_{i}$ is the number of carbon atoms in the i'th product and $y_{i}$ its mole fraction in the exit gas. In this article, the reversible by-product corrected selectivity and conversion will mostly be used, as it takes into account that DME, DMM and MF are reversible products and will form $2 \mathrm{MeOH}, 2 \mathrm{MeOH}$ and 1 formaldehyde and $1 \mathrm{MeOH}$ and $1 \mathrm{CO}$ molecule, respectively, at high conversion. They are calculated according to Equation (3) and (4).

$$
\begin{gathered}
S_{\text {cor }}=\frac{S_{\mathrm{CH}_{2} \mathrm{O}}+\frac{1}{3} S_{\mathrm{DMM}}}{S_{\mathrm{CH}_{2} \mathrm{O}}+\frac{1}{3} S_{\mathrm{DMM}}+\frac{1}{2} S_{\mathrm{MF}}+S_{\mathrm{CO}}+S_{\mathrm{CO}_{2}}} \\
X_{\text {cor }}=\left(1-\frac{2}{3} S_{\mathrm{DMM}}-\frac{1}{2} S_{\mathrm{MF}}-S_{\mathrm{DME}}\right) X
\end{gathered}
$$

(Pseudo-) $1^{\text {st }}$ order kinetics have been reported in the literature ${ }^{82-86}$ for the selective oxidation of methanol to formaldehyde, thus the reaction rate constants are calculated according to the design equation for a $1^{\text {st }}$ order reaction in a fixed bed reactor (Equation (5)) ${ }^{87}$.

$$
k=-\frac{V_{0}}{W} \ln (1-X)
$$


For calculation of $k_{c o r}, \mathrm{X}_{\mathrm{cor}}$ should be used as $\mathrm{X} . W$ is the weight of sample loaded and $V_{0}$ the volumetric flow rate at reaction temperature and pressure. Over four runs of $\# 3$ pellets the standard deviation at $350^{\circ} \mathrm{C}$ was $\pm 0.6 \%$ for $S_{c o r}$ and $\pm 0.8 \%$ for $X_{\text {cor }}$.

\subsection{Effectiveness factor}

To understand the evolution of the observed activity of the pellets with the changes in the support density, calculations of the overall effectiveness factor were conducted for both powder and pellet measurements as evaluation of the test criteria showed, that internal and external mass transfer limitations and external heat transfer limitations were present for both pellets and powder, whereas intra particle heat transfer, axial diffusion/dispersion, bed dilution, deviation from ideal PBR behavior could be neglected (Tables S2-S4, Figure S1). The effectiveness factor was calculated for spherical geometry using the Thiele modulus for a first order reaction (Equations (6)-(9)) ${ }^{87}$.

$$
\begin{gathered}
\Omega=\frac{\eta}{1+\frac{\eta \rho k_{\text {int }}}{k_{f}} \frac{V}{S}} \\
\eta=\frac{1}{\phi}\left[\frac{1}{\tanh (3 \phi)}-\frac{1}{3 \phi}\right] \\
\phi=\frac{V}{S} \sqrt{\frac{\rho k_{\text {int }}}{D_{e}}} \\
k_{\text {int }}=\frac{k_{o b s}}{\Omega}
\end{gathered}
$$

Where $\Omega$ is the overall effectiveness factor, $\eta$ is the internal effectiveness factor, $k_{f}$ the fluid mass transfer coefficient, $\phi$ the thiele modulus, $V$ the volume of the pellet ring (excl. the hole) or powder particle, $S$ the external surface area including the surface inside the hole for the pellet or spherical powder particle, $D_{e}$ the effective diffusion coefficient of methanol, $k_{\text {int }}$ the mass based intrinsic rate constant and $k_{o b s}$ the observed rate constant assuming first order kinetics according to Equation (5). To determine the effective diffusion coefficient in the pellets a random pore model was used. The model took into account both bulk diffusion (Equation (10)) and Knudsen diffusion (Equation (11)). The diffusion coefficient was calculated as a sum of resistances from bulk and Knudsen diffusion for every data point in the Hgporosimetry measurements (Equation (12)) and the diffusion coefficient in the meso- and macropores 
was calculated by summing up the contribution from the different pore sizes (Equation (13)) and applying it to the random pore model (Equation (14)) ${ }^{88,89}$.

$$
\begin{gathered}
D_{A B}=D_{A B, \text { ref }} \frac{T^{\frac{3}{2}} \frac{P_{r e f}}{P}}{T_{\text {ref }}^{\frac{3}{2}}} \\
D_{K A}=\frac{4}{3} r\left(\frac{2}{\pi} \frac{R_{g} T}{M_{A}}\right)^{\frac{1}{2}} \\
D_{j}=\left(\frac{1}{D_{A B}}+\frac{1}{D_{K A, j}}\right)^{-1} \\
D_{M \text { or meso }}=\frac{\sum_{j}\left(\Delta \epsilon_{M \text { or meso }, j} \cdot D_{M \text { or meso }, j}\right)}{\epsilon_{M \text { or meso }}} \\
D_{e}=\epsilon_{M}^{2} D_{M}+\epsilon_{\text {meso }}^{2} \frac{\left(1+3 \epsilon_{M}\right)}{1-\epsilon_{M}} D_{\text {meso }}
\end{gathered}
$$

Where $D_{K A}$ is the Knudsen diffusion coefficient of gaseous $\mathrm{MeOH}, r$ the pore radius, $R_{g}$ the ideal gas constant, $T$ temperature, $M$ the molar mass. $D_{M}$ and $D_{\text {meso }}$ are the effective diffusion coefficients in the macro- and mesopores respectively. $D_{A B}$ is the bulk diffusion coefficient, and $\epsilon_{M}$ and $\epsilon_{m e s o}$ are the macro- and mesoporosity. The model is applicable for two distinct sets of pores. In this paper, the typical distinction between macropores $(r \geq 500 \AA)$ and mesopores $(r<500 \AA)$ was used. Subscript j denotes a Hg-porosimetry data point.

\section{5 $\quad \mathrm{MoO}_{3}$ Evaporation Measurements}

The setup used for the $\mathrm{MoO}_{3}$ evaporation experiments is shown in Figures $\mathrm{S} 2$ and $\mathrm{S} 3$ and has been described in ${ }^{27}$. The setup has three identical reactor tubes in parallel with the possibility of having four pellets in each reactor. Four pellets were slid onto a thermocouple with an outer diameter of $1.5 \mathrm{~mm}$ and centered in a tubular reactor with an inner diameter of $6.5 \mathrm{~mm}$. The pellets were kept centered in the reactor by spacers mounted on the thermocouple. The pellets were subjected to $5 \mathrm{vol} . \% \mathrm{MeOH}, 10$ vol. $\% \mathrm{O}_{2}$ in $\mathrm{N}_{2}$ with a flowrate of $3000 \mathrm{NmL} / \mathrm{min} /$ reactor at $350^{\circ} \mathrm{C}$ for $118.5 \mathrm{~h}$. The pellet closest to the gas inlet in each reactor was subjected to SEM investigations, and the remaining three pellets were used for ICP-OES analyses. The pellets were weighed before and after the exposure. After the exposure the pellets were dried at $120^{\circ} \mathrm{C}$ for two hours and calcined at $500^{\circ} \mathrm{C}$ for $1 \mathrm{~h}$ with a heating ramp of $5^{\circ} \mathrm{C} / \mathrm{min}$ after experiment to ensure full oxidation of the catalysts. 


\section{Results and Discussion}

\subsection{Characterization}

HAP support material pellets with six different densities before calcination were prepared (see Table 1). The pellet 'Specifications' in Table 1 were measured on the first pellet produced at the chosen pellet press setting.

Table 1: HAP pellet specifications and statistics after calcination. Dia. $=$ diameter, $\mathrm{H}=$ height, $\mathrm{W}=$ weight, $\mathrm{n}=$ number of pellets measured, $\mathrm{nd}=$ not determined

\begin{tabular}{|c|c|c|c|c|c|c|c|c|c|c|c|c|c|}
\hline & \multicolumn{4}{|c|}{ Specifications } & \multicolumn{10}{c|}{ After Calcination } \\
\hline$\#$ & $\boldsymbol{\rho}$ & Dia. & $\mathbf{H}$ & $\mathbf{W}$ & $\mathbf{n}$ & \multicolumn{2}{|c|}{} & \multicolumn{2}{|c|}{ Dia. } & \multicolumn{2}{|c|}{$\mathbf{H}$} & \multicolumn{2}{|c|}{ W } \\
\hline & {$\left[\mathbf{g} / \mathbf{c m}^{3}\right]$} & {$[\mathbf{m m}]$} & {$[\mathbf{m m}]$} & {$[\mathbf{m g}]$} & & $\begin{array}{c}\text { Mean } \\
{[\mathbf{m m}]}\end{array}$ & $\begin{array}{c}\text { St.d. } \\
{[\%]}\end{array}$ & $\begin{array}{c}\text { Mean } \\
{[\mathbf{m m}]}\end{array}$ & $\begin{array}{c}\text { St.d. } \\
{[\%]}\end{array}$ & $\begin{array}{c}\text { Mean } \\
{[\mathbf{m m}]}\end{array}$ & $\begin{array}{c}\text { St.d. } \\
{[\%]}\end{array}$ & $\begin{array}{c}\text { Mean } \\
{[\mathbf{m g}]}\end{array}$ & $\begin{array}{c}\text { St.d. } \\
{[\%]}\end{array}$ \\
\hline 1 & 1.84 & 4.55 & 4.04 & 103 & 0 & nd & nd & nd & nd & nd & nd & nd & nd \\
\hline 2 & 1.76 & 4.54 & 4.01 & 98 & 10 & 1.76 & 1.8 & 4.46 & 0.1 & 3.97 & 0.9 & 91.2 & 2.6 \\
\hline 3 & 1.59 & 4.56 & 4.05 & 90 & 10 & 1.62 & 2.1 & 4.48 & 0.1 & 3.97 & 0.2 & 86.2 & 2.1 \\
\hline 4 & 1.44 & 4.55 & 4.05 & 81 & 10 & 1.39 & 1.7 & 4.48 & 0.1 & 3.96 & 0.5 & 73.9 & 2.1 \\
\hline 5 & 1.26 & 4.55 & 4.03 & 71 & 10 & 1.18 & 3.5 & 4.50 & 0.2 & 3.94 & 1.6 & 62.8 & 5.5 \\
\hline $6^{\text {a }}$ & 1.18 & 4.52 & 4.00 & 65 & 0 & nd & nd & nd & nd & nd & nd & nd & nd \\
\hline
\end{tabular}

${ }^{a}$ pellets were not measured after calcination due their low mechanical stability.

The densities of the pellets before and after calcination could be quite different due to sintering and since wax and some of the graphite combusted during calcination of the catalyst pellets. The variations on especially the weight and the height of the pellets increased at low pellet densities, but this partially cancelled out when calculating the pellet density, so the standard deviation on this parameter was less influenced. The FeMo pellet density for comparison was $1.82 \mathrm{~g} / \mathrm{cm}^{3}$.

\subsubsection{X-ray Powder Diffraction, ICP and BET}

For all the Mo loaded catalysts had X-ray powder diffraction was conducted on a crushed pellet after calcination (Figure 1, Figure S4 and Table 2). 


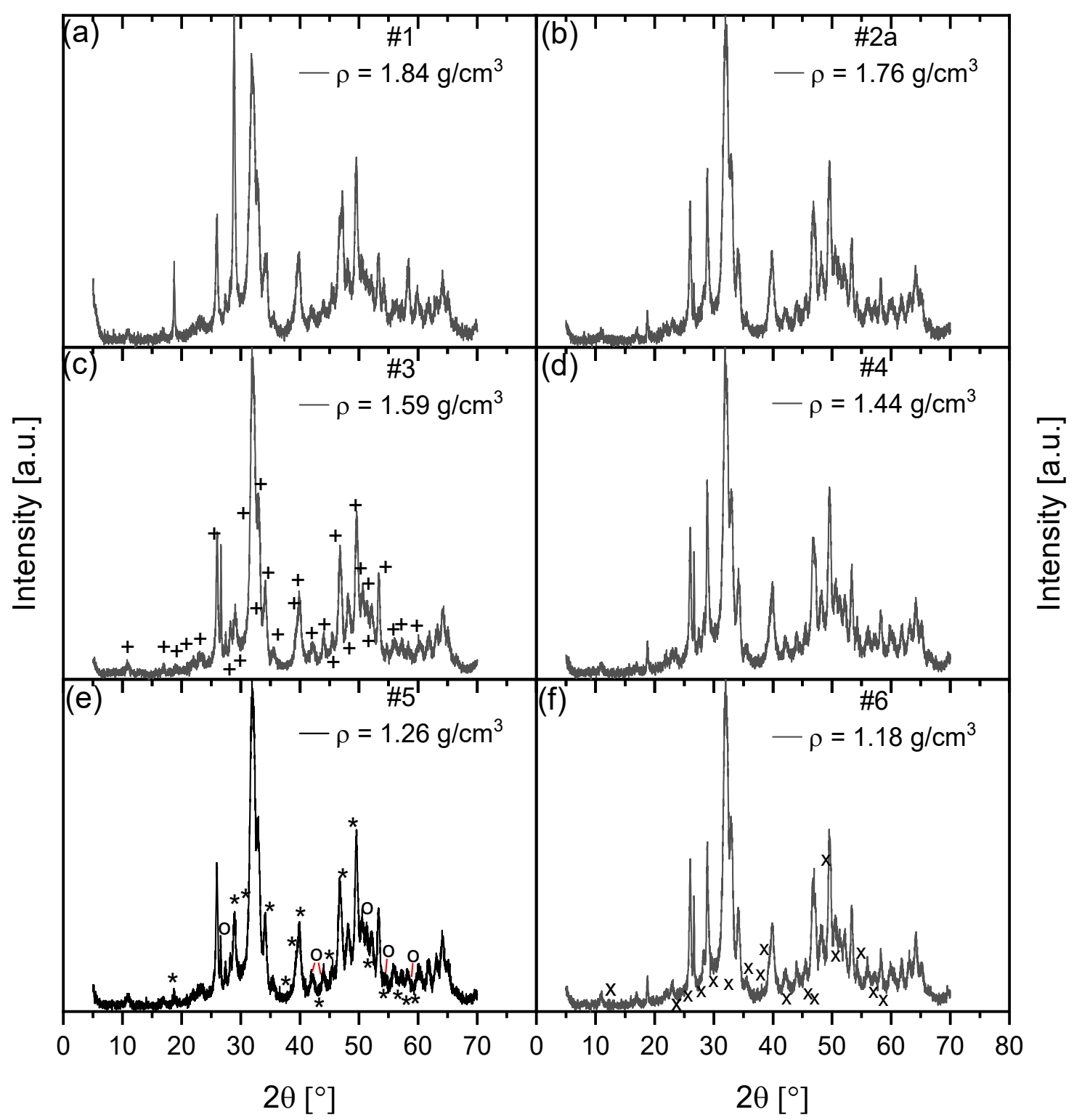

Figure 1: XRD diffractograms for fresh $10 \mathrm{wt} \% \mathrm{MoO}_{3} / \mathrm{HAP}$ catalyst samples with aimed pellet densities of (a) $\rho=1.84 \mathrm{~g} / \mathrm{cm}^{3}$ (b) $\rho=1.76 \mathrm{~g} / \mathrm{cm}^{3}$ (c) $\rho=1.59 \mathrm{~g} / \mathrm{cm}^{3}$, (d) $\rho=1.44 \mathrm{~g} / \mathrm{cm}^{3}$, (e) $\rho=1.26 \mathrm{~g} / \mathrm{cm}^{3}$, (f) $\rho=1.18 \mathrm{~g} / \mathrm{cm}^{3}$. $\mathrm{CaMoO}_{4}(*), \mathrm{HAP}(+), \mathrm{C}(\mathrm{o}), \mathrm{MoO}_{3}(\mathrm{x})$.

All the samples showed the crystalline phases: hydroxyapatite, $\mathrm{CaMoO}_{4}$ and small amounts of bulk $\mathrm{MoO}_{3}$ with slight differences in the amounts and no significant differences in the crystallite size, see Table 2. There was no correlation between the Mo content found by ICP and the amount of $\mathrm{CaMoO}_{4}$ or $\mathrm{MoO}_{3}$ determined from XRD. In all cases the amount of $\mathrm{MoO}_{3}$ accounted for by XRD was lower than the nominal loading determined from ICP, in agreement with the expectation of the HAP surface being covered in an amorphous layer of $\mathrm{MoO}_{x}$. Graphite from the pelletization were found in all the pellets. The $\mathrm{Ca} / \mathrm{P}$ ratio from ICP on sample \#1 with $\rho=1.84 \mathrm{~g} / \mathrm{cm}^{3}$ was slightly lower than for the other samples, 
which could be due to a small difference in the preparation method (the precipitation mixture was not filtered hot). The $\mathrm{Ca} / \mathrm{P}$ ratio of $1.56-1.57$ for the other samples agrees well with ${ }^{37}$. The BET surface areas of $\# 1$ and $\# 2 \mathrm{a}$ and $\mathrm{b}$ were slightly lower than $\# 3, \# 4$ and $\# 6$. The reason for the high surface area of \#5 was believed to come from either temperature gradients inside the muffle furnace or use of a different muffle furnace as calcination of a single $\# 5$ pellet at $500^{\circ} \mathrm{C}$ gave even higher surface area and $600^{\circ} \mathrm{C}$ gave similar areas as $\# 3,4$ and 6.

Table 2: Specific surface area measured by BET, ICP and XRD phase compositions on the fresh catalyst samples after calcination.

\begin{tabular}{|c|c|c|c|c|c|c|c|c|c|c|c|}
\hline \multirow{3}{*}{ \# } & \multirow{3}{*}{$\begin{array}{c}\rho \\
{\left[\mathrm{g} / \mathbf{c m}^{3}\right]}\end{array}$} & \multirow{3}{*}{$\begin{array}{c}\text { BET } \\
\text { SSA } \\
{\left[\mathrm{m}^{2} / \mathrm{g}\right]}\end{array}$} & \multicolumn{2}{|c|}{ ICP } & \multicolumn{7}{|c|}{ XRD } \\
\hline & & & \multirow{2}{*}{\begin{tabular}{|l|}
$\mathrm{MoO}_{3}$ \\
{$[\mathrm{wt} \%]$} \\
\end{tabular}} & \multirow[t]{2}{*}{$\mathrm{Ca} / \mathbf{P}$} & \multicolumn{2}{|c|}{ HAP } & \multicolumn{2}{|c|}{$\mathrm{CaMoO}_{4}$} & \multicolumn{2}{|c|}{$\mathrm{MoO}_{3}$} & \multirow{2}{*}{$\begin{array}{c}\mathrm{C} \\
{[w t \%]}\end{array}$} \\
\hline & & & & & {$[w t \%]$} & $\mathbf{D}[\AA]$ & {$[w t \%]$} & $\mathbf{D}[\AA]$ & {$[w t \%]$} & $\mathbf{D}[\AA]$ & \\
\hline $1^{\mathrm{a}}$ & 1.84 & 27 & & 1.52 & 86.7 & 150 & 12 & 243 & 1.3 & 355 & - \\
\hline $2 a$ & 1.76 & 28 & 10.6 & 1.56 & 91.1 & 161 & 4.7 & 249 & 1.1 & 200 & 3.1 \\
\hline $2 b$ & 1.76 & 25 & 12.9 & 1.56 & 88.6 & 157 & 6.6 & 374 & 1.8 & 202 & 3.0 \\
\hline 3 & 1.59 & 31 & 9.3 & 1.56 & 93.9 & 169 & 2.7 & 200 & 1.8 & 250 & 1.6 \\
\hline 4 & 1.44 & 31 & 8.9 & 1.57 & 91.8 & 175 & 4.7 & 217 & 0.7 & 250 & 2.8 \\
\hline 5 & 1.26 & 46 & 9.6 & 1.57 & 94.4 & 181 & 1. & 202 & 1.8 & 250 & 2. \\
\hline 6 & 1.18 & 31 & 10.2 & 1.56 & 90.1 & 177 & 5.5 & 260 & 1.9 & 250 & 2.5 \\
\hline
\end{tabular}

${ }^{a}$ this pellet was made from Mo loaded catalyst instead of pure HAP support. The XRD measurement was on the powder before pelletizing.

Four pellets of each sample were subjected to $5 \mathrm{vol} . \% \mathrm{MeOH}, 10 \mathrm{vol} . \% \mathrm{O}_{2}$ in $\mathrm{N}_{2}$ with a flowrate of $3000 \mathrm{NmL} / \mathrm{min}$ for $118.5 \mathrm{~h}$. The mass loss was measured on four pellets combined and had the elemental composition was measured on the three pellets nearest the reactor outlet (Figure 2).

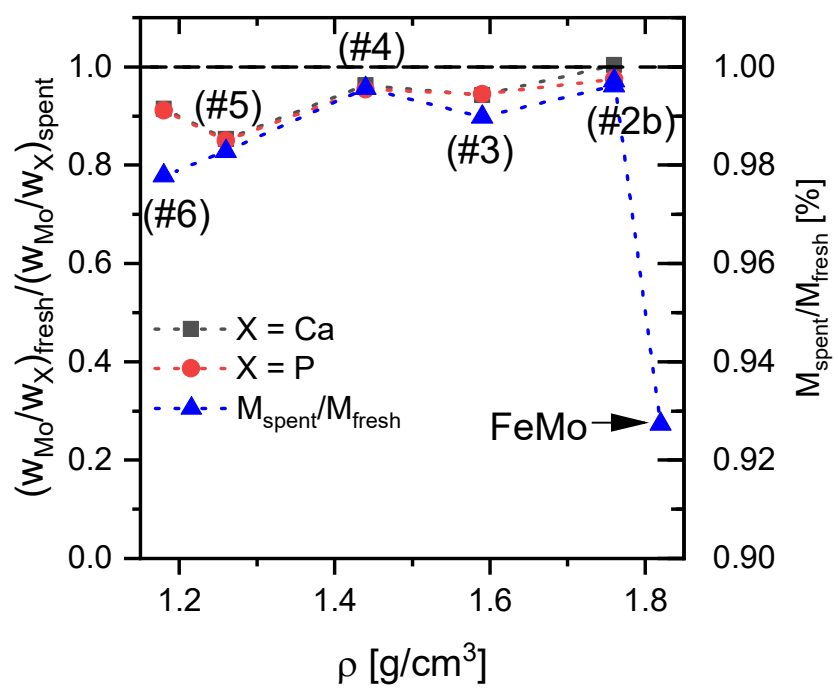

Figure 2: Ratio of Mo to $\mathrm{Ca}$ and $\mathrm{P}$ (three pellets combined and measured for each sample), and measured mass loss (four pellets combined and measured for each sample) after $118.5 \mathrm{~h}$ at $350^{\circ} \mathrm{C}, 3000$ 
$\mathrm{NmL} / \mathrm{min}, 5$ vol. $\% \mathrm{MeOH}, 10$ vol. $\% \mathrm{O}_{2}$ in $\mathrm{N}_{2}$ ( $<15 \%$ conversion estimated), compared to the fresh samples.

The pellets had a lower ratio of Mo to $\mathrm{Ca}$ and $\mathrm{P}$ after exposure. The Mo loss generally increased with decreasing pellet density (increasing porosity), but was still very low for all samples. With the exception of \#5, the remaining pellets lost less than $9 \%$. The low loss of Mo measured by ICP was in agreement with initial investigations on the $\rho=1.84 \mathrm{~g} / \mathrm{cm}^{3}$ (\#1) pellet (Figure S5), where the mass loss within the uncertainty was zero. The measured mass loss on the \#2-6 pellets was in general corresponding well to the change in ICP ratio for $\mathrm{Mo} / \mathrm{Ca}$ and $\mathrm{Mo} / \mathrm{P}$, with the largest discrepancy at $\rho=1.18 \mathrm{~g} / \mathrm{cm}^{3}$. The difference was believed to stem from debris lost from the pellets during insertion and extraction of the pellets from the reactor tubes due to the low mechanical stability. Reference FeMo pellets lost 7.3\% mass during the $118.5 \mathrm{~h}$ on stream, whereas the highest mass loss measured on the $\mathrm{MoO}_{3} / \mathrm{HAP}$ pellets was $2.2 \%$ for the \#6 sample and only $0.4 \%$ for the $\# 2 \mathrm{a}$ and $\# 2 \mathrm{~b}$ samples. The mass loss from the pellets and thus Mo volatilization increased with decreasing density, but was less than $30 \%$ of the mass loss of the FeMo catalyst for all pellet densities.

\subsubsection{Hg-porosimetry}

Hg-porosimetry was performed on samples of each pellet density and FeMo (Figure 3 and Table 3).

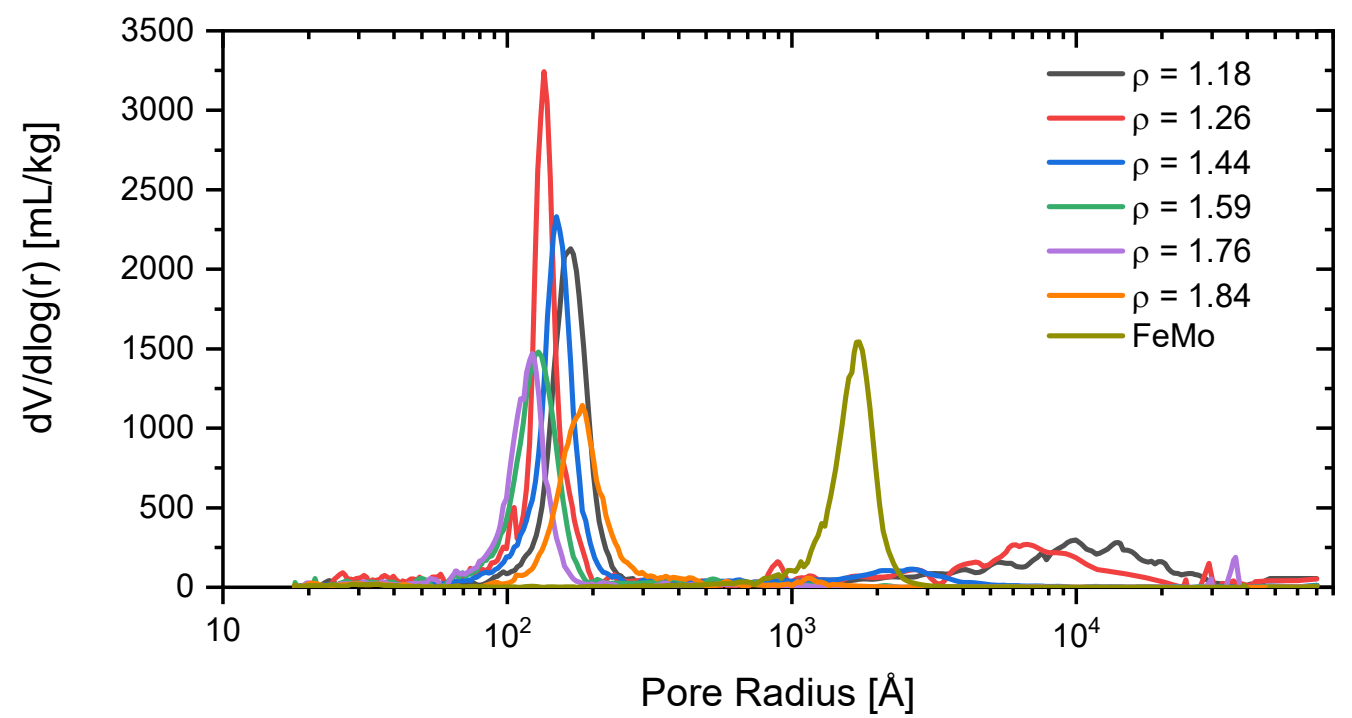

Figure 3: Hg-porosimetry pore-size distribution of crushed fresh pellets with densities from 1.18 to $1.84 \mathrm{~g} / \mathrm{cm}^{3}$ and the FeMo reference.

Most notably the pellets with densities of $1.44 \mathrm{~g} / \mathrm{cm}^{3}$ and below had both macro pores and meso pores, whereas the high density pellets only had meso pores (Figure 3). This was also evident in the meso and 
macro porosity and mean pore radius (Table 3). This had a large influence on the effective diffusion coefficient, which increased to almost a factor of three, when the density decreased from 1.76 to 1.18 $\mathrm{g} / \mathrm{cm}^{3}$. The total porosity increased with decreasing pellet density, as expected. FeMo had a pore radius around $1700 \AA$.

Table 3: Hg-porosimetry results for crushed calcined pellets of the support material showing target density, density from Hg-porosimetry, mean pore radius, total, macro, and meso porosity and calculated effective diffusion coefficients from the random pore model.

\begin{tabular}{|c|c|c|c|c|c|c|c|c|c|c|}
\hline \# & $\rho$ & $\rho_{\mathrm{Hg}}$, particle & $\rho_{\mathrm{Hg}, \text { skeletal }}$ & $\mathbf{r}_{\text {mean }}$ & $\epsilon_{\text {tot }}$ & $\epsilon_{M}$ & $\epsilon_{\text {meso }}$ & $D_{e, 250^{\circ} \mathrm{C}}$ & $D_{e, 300^{\circ} \mathrm{C}}$ & $\mathbf{D}_{\mathrm{e}, 350^{\circ} \mathrm{C}}$ \\
\hline & {$\left[\mathrm{g} / \mathrm{cm}^{3}\right]$} & {$\left[\mathrm{g} / \mathrm{cm}^{3}\right]$} & {$\left[\mathrm{g} / \mathrm{cm}^{3}\right]$} & {$[\AA ̊]$} & [\%] & {$[\%]$} & {$[\%]$} & {$\left[\mathrm{cm}^{2} / \mathrm{s}\right]$} & {$\left[\mathrm{cm}^{2} / \mathrm{s}\right]$} & {$\left[\mathrm{cm}^{2} / \mathrm{s}\right]$} \\
\hline $1^{\mathrm{a}}$ & 1.84 & 1.73 & 2.94 & 166 & 41 & 1.0 & 40 & $9.8 \cdot 10^{-3}$ & $1.0 \cdot 10^{-2}$ & $1.1 \cdot 10^{-2}$ \\
\hline 2 & 1.76 & 1.75 & 3.00 & 105 & 42 & 0.5 & 41 & $6.7 \cdot 10^{-3}$ & $7.1 \cdot 10^{-3}$ & $7.5 \cdot 10^{-3}$ \\
\hline 3 & 1.59 & 1.63 & 3.07 & 117 & 47 & 0.5 & 47 & $9.5 \cdot 10^{-3}$ & $1.0 \cdot 10^{-2}$ & $1.1 \cdot 10^{-2}$ \\
\hline 4 & 1.44 & 1.39 & 3.12 & 156 & 56 & 6.8 & 49 & $1.5 \cdot 10^{-2}$ & $1.6 \cdot 10^{-2}$ & $1.7 \cdot 10^{-2}$ \\
\hline 5 & 1.26 & 1.09 & 2.74 & 166 & 60 & 18 & 42 & $1.6 \cdot 10^{-2}$ & $1.8 \cdot 10^{-2}$ & $1.8 \cdot 10^{-2}$ \\
\hline 6 & 1.18 & 1.07 & 2.63 & 235 & 59 & 21 & 38 & $1.9 \cdot 10^{-2}$ & $2.0 \cdot 10^{-2}$ & $2.1 \cdot 10^{-2}$ \\
\hline
\end{tabular}

${ }^{\text {a }} \mathrm{Hg}$-porosimetry was performed on the crushed final pellet including $\mathrm{MoO}_{3}$ for this sample.

The skeletal density determined for the pellets were all lower than the crystal density of hydroxyapatite $\left(3.14 \mathrm{~g} / \mathrm{cm}^{3}\right)$. The difference from the measured skeletal density could arise from closed porosity/air pockets and smaller pores not probed by Hg. The difference was especially large for the low density pellets.

\subsubsection{SEM}

Both fresh and spent pellets were investigated by SEM (Figure 4 and Figure S6 - S12) to visualize the porosity changes and the molybdenum volatilization from the pellets. Significant changes were observed with decreasing pellet density (Figure 4), with visible porosity in the images at low density. 


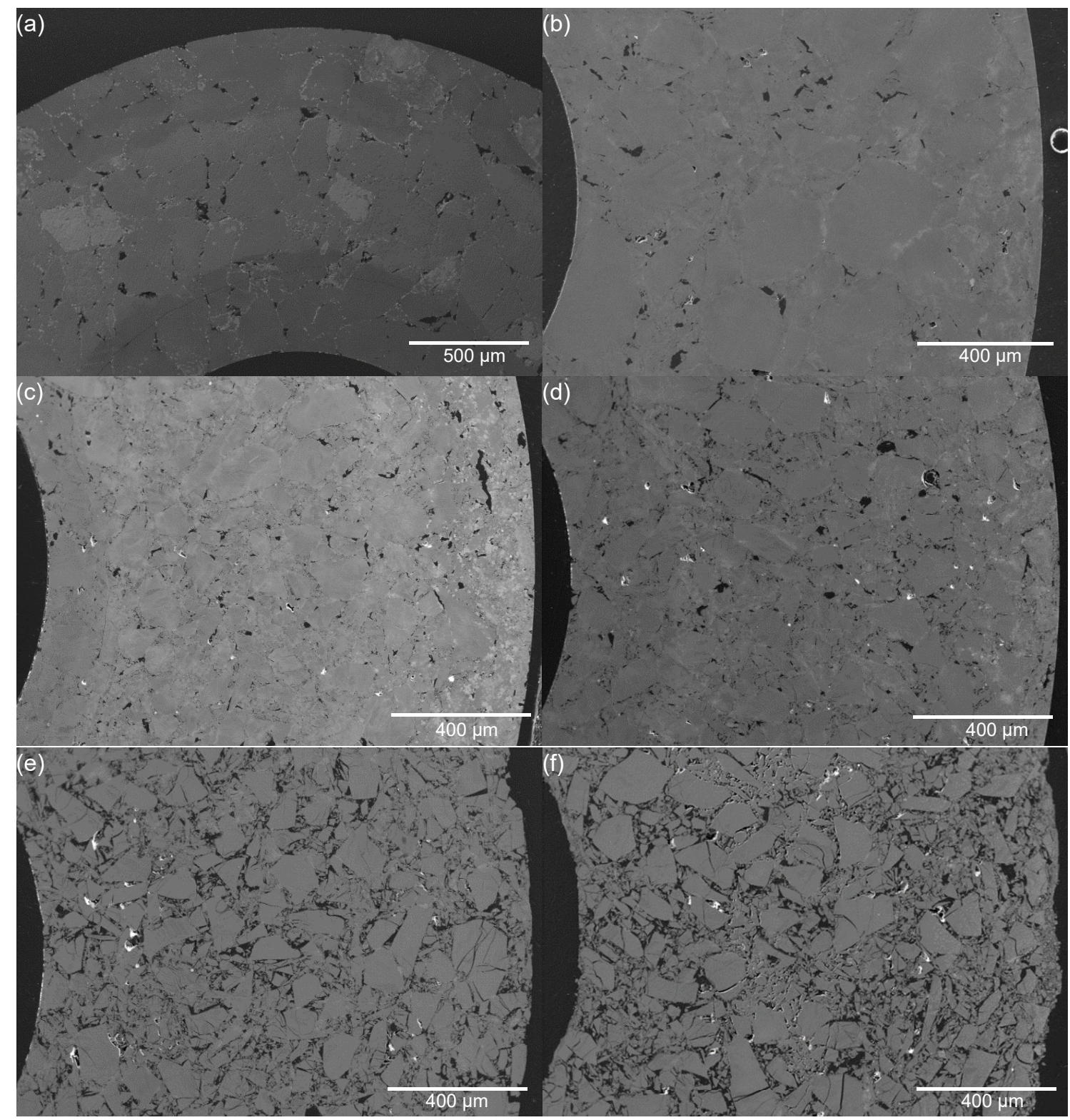

Figure 4: SEM images of the cross section of the cylinder wall for (a) fresh $\rho=1.84$ (\#1), (b) fresh $\rho$ $=1.76$ (\#2a), (c) $118.5 \mathrm{~h}$ spent $\rho=1.59$ (\#3), (d) $118.5 \mathrm{~h}$ spent $\rho=1.44$ (\#4), (e) 118.5 h spent $\rho=$ 1.26 (\#5), (f) 118.5 h spent $\rho=1.18$ (\#6).

The increase in macropores at $\rho \leq 1.44 \mathrm{~g} / \mathrm{cm}^{3}$ measured by Hg-porosimetry were confirmed by the SEM images. The $\rho=1.84 \mathrm{~g} / \mathrm{cm}^{3}$ (\#1) pellets were found to be inhomogeneous as there was large particles $(>100 \mu \mathrm{m})$, which were brighter than the rest (Figure 4(a)) and Figure S6) in addition to the very bright particles in the joints of the pellets (Figure S6). The inhomogeneity of the $\rho=1.84 \mathrm{~g} / \mathrm{cm}^{3}$ (\#1) samples (Figure 4(a) and Figure S6) with visible Mo loading differences on the pressed particles were part of the motivation for impregnating on the HAP pellets, to have a more homogeneous Mo distribution. This 
was successful for low density pellets, but only partly successful for the high density pellets (Figure 5 and Figure S7 - S12) as a higher Mo loading near the outer surface of the pellets $2 \mathrm{a}, 2 \mathrm{~b}$ and 3 were visible as higher brightness in the SEM images and was measureable by SEM EDX maps and line scans.

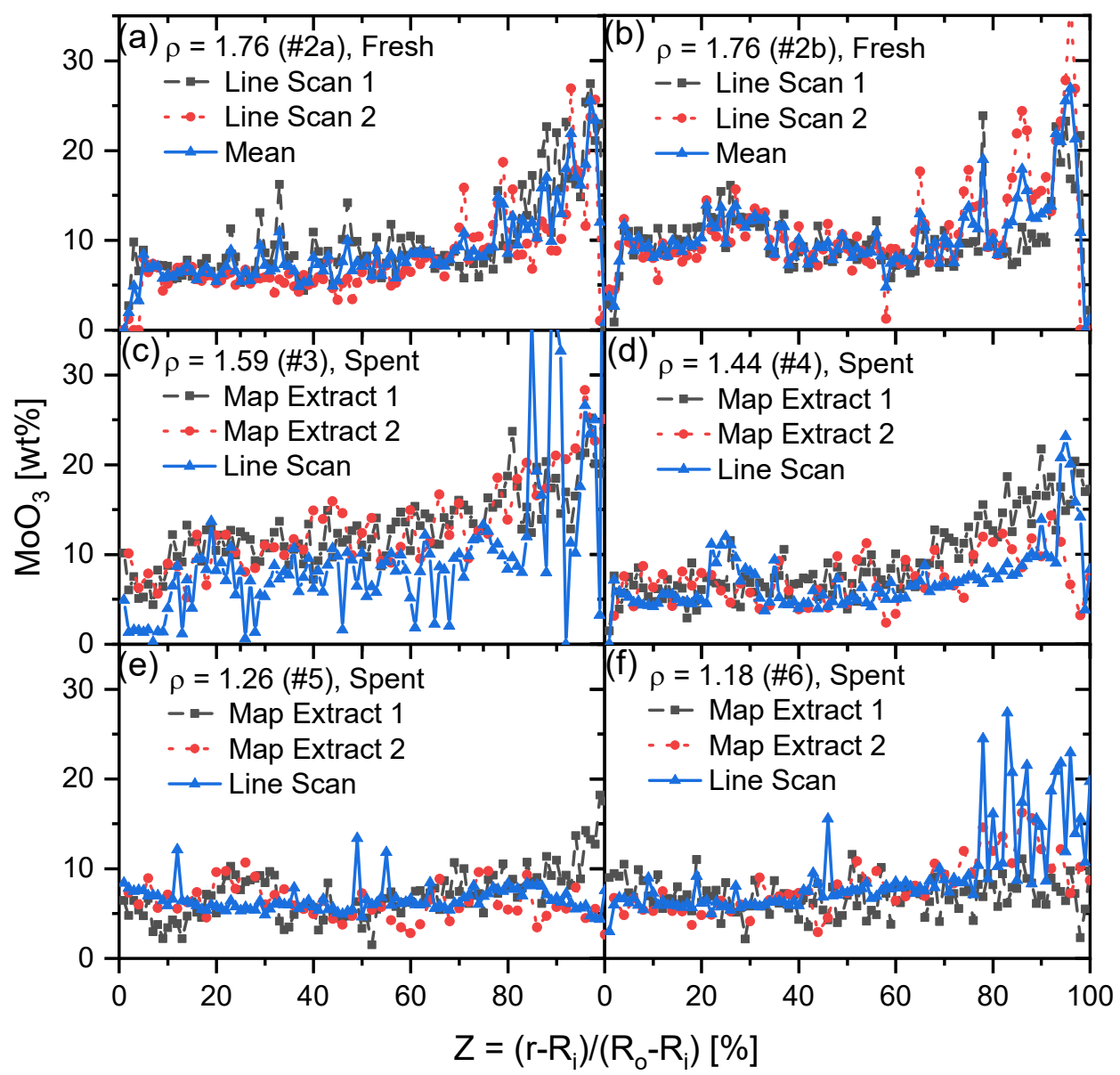

Figure 5: $\mathrm{MoO}_{3}$ content from SEM line scans and line extractions from EDX maps for (a) $\rho=1.76$ (\#2a) (fresh), (b) $\rho=1.76$ (\#2b) (fresh), (c) $\rho=1.59$ (\#3) (spent for 118.5 h), (d) $\rho=1.44$ (\#4) (spent for $118.5 \mathrm{~h}$ ), (e) $\rho=1.26$ (\#5) (spent for $118.5 \mathrm{~h}$ ), (f) $\rho=1.18$ (\#6) (spent for $118.5 \mathrm{~h}$ ). Line scans were more precise due to a higher number of measurements in each data point. Placement of line scans and map extractions are shown in Figure $S 13 . R_{i}$ and $R_{0}$ is the inner and outer radius of the rings.

The pellets with low density had more homogeneous Mo profiles. The higher concentration near the outer surface of the pellets was believed to be an effect of the water being pulled by capillary forces to the outer surface during drying. The SEM EDX line scans and extractions showed $\mathrm{MoO}_{3}$ loadings near the nominal $10 \mathrm{wt} \%$ for the main part of the pellets, but with local loadings up to above $30 \mathrm{wt} \%$ near the outer surface. There were visible differences in the distribution of Mo depending on where on the periphery of the cylinder the maps and line scans were performed. The SEM EDX maps and line scans 
on the spent pellets (Figure 5(c)-(f) and Figures S8-S13) showed no clear Mo depletion front as was observed for FeMo pellets by Raun et al. ${ }^{27}$ nor other signs on Mo volatilization, though these pellets were placed upstream in the reactor, i.e. at higher methanol concentration, compared to the pellets which were subjected to ICP.

\subsection{Activity, Selectivity and Stability Measurements}

The catalytic activity and selectivity of all $\mathrm{MoO}_{3}$ impregnated catalysts and the industrial FeMo reference were measured on single pellets at temperatures of $250^{\circ} \mathrm{C}$ to $400^{\circ} \mathrm{C}$ (Figure 6). The general trend was that activity (in terms of the observed mass based first order rate constant), conversion and selectivity were all highest for the pellets with lower density (and higher porosity), despite the lower mass per pellet. The increase in selectivity with decreasing density was especially high at $250^{\circ} \mathrm{C}$ and $300^{\circ} \mathrm{C}$, but this effect decreased at higher temperatures, due to increasing selectivity of the high density pellets and a decreasing selectivity on the low density pellets with increasing temperature. At the lowest temperature of $250{ }^{\circ} \mathrm{C}$ (Figure $6 \mathrm{a}$ ) the conversion was below $5 \%$, causing higher uncertainty on the measurement of selectivity. At $250^{\circ} \mathrm{C}$, the difference in activity (observed rate constant) between the most and least active pellet were approximately a factor of two, but the most active pellet also had a significantly higher surface area. At $400^{\circ} \mathrm{C}$ the high density pellets ( $\# 2 \mathrm{a}$ and $\# 3$ ) were four times less active than pellet \#6 with $\rho=1.18 \mathrm{~g} / \mathrm{cm}^{3}$. The conversion for pellet \#5 with $\rho=1.26 \mathrm{~g} / \mathrm{cm}^{3}$ was higher than for the $1.18 \mathrm{~g} / \mathrm{cm}^{3}$ pellet though the latter was the most active due to the difference in pellet mass. In comparison, the FeMo catalyst was the most selective, but the lighter $\mathrm{MoO}_{3} / \mathrm{HAP}$ pellets (\#5 and \#6) were equally active at $300^{\circ} \mathrm{C}$ and above. 

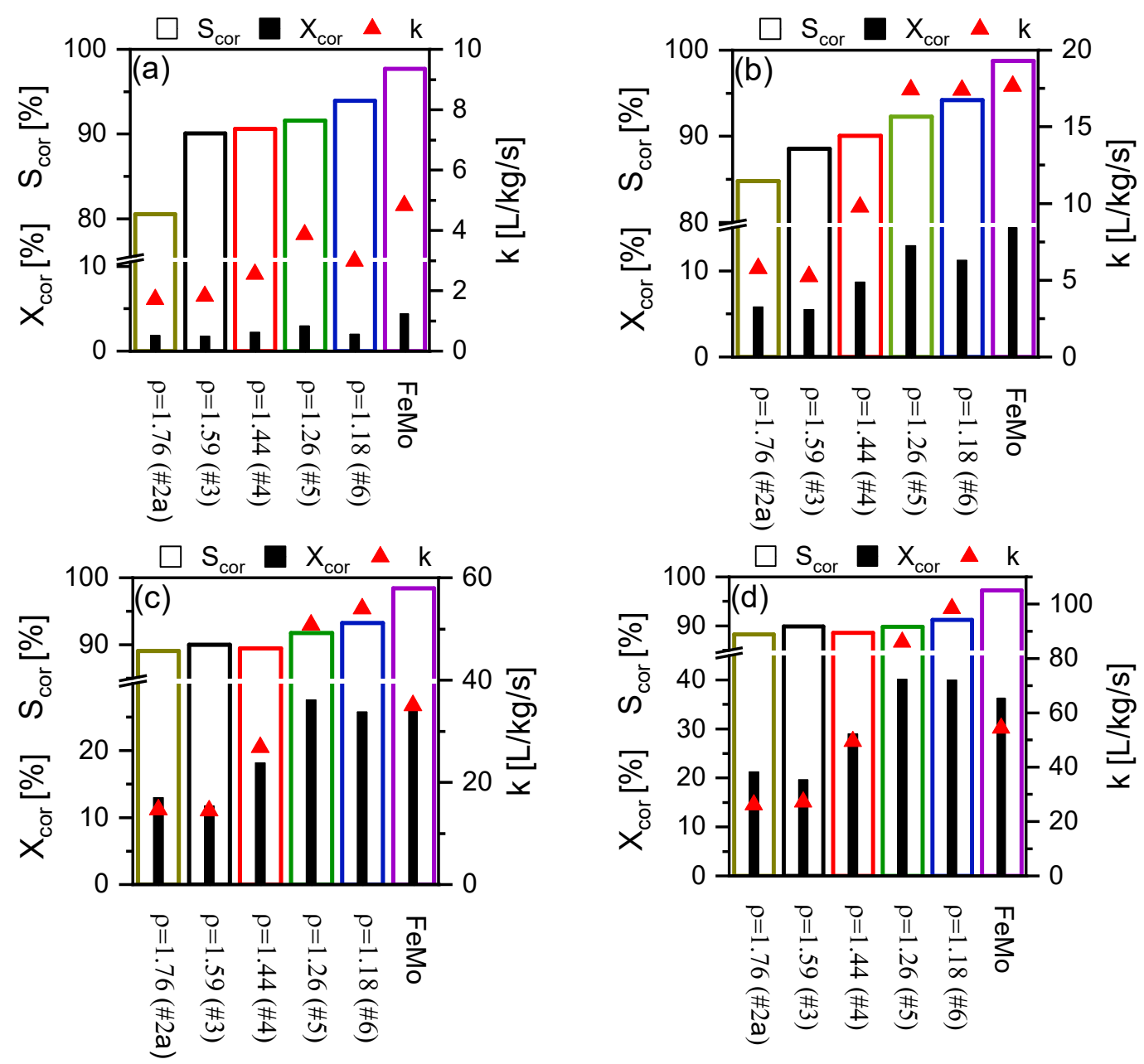

Figure 6: Observed $1^{\text {st }}$ order rate constant and reversible byproduct corrected conversion and selectivities on single pellets at (a) $250^{\circ} \mathrm{C}$, (b) $300^{\circ} \mathrm{C}$, (c) $350^{\circ} \mathrm{C}$ and (d) $400^{\circ}$ (c) in $300 \mathrm{NmL} / \mathrm{min}, 5 \mathrm{vol} . \%$ $\mathrm{MeOH}, 10$ vol.\% $\mathrm{O}_{2}$ in $\mathrm{N}_{2}$ for pellets \#2a, \#3-6 and a FeMo pellet for comparison. The carbon mass balance was within $6 \%$.

The measured activity of the pellets was generally lower than for the powdered catalysts, and the activity decreased strongly with increasing pellet density. This is in agreement with the strongly decreasing effective diffusion coefficient with increasing pellet density (Table 3). The ratio between pellet activity and powder activity generally increased with decreasing pellet density (Table 4), but the trend was most clear at higher temperatures $\left(\geq 300^{\circ} \mathrm{C}\right)$. 
Table 4: Observed ratio between the catalyst pellet activity and catalyst powder activity at $250-400^{\circ} \mathrm{C}$ $\left(\right.$ ratio $\left.=\mathrm{k}_{\text {obs,pellet }} / \mathrm{k}_{\mathrm{obs} \text {,powder }}\right)$.

\begin{tabular}{|c|c|c|c|c|c|}
\hline$\#$ & \multirow{\rho}{*}{$\mathbf{2 5 0}^{\circ} \mathbf{C}$} & $\mathbf{3 0 0}^{\circ} \mathbf{C}$ & $\mathbf{3 5 0}^{\circ} \mathbf{C}$ & $\mathbf{4 0 0}^{\circ} \mathbf{C}$ \\
\cline { 3 - 6 } & ratio & ratio & ratio & ratio \\
\hline & {$\left[\mathbf{g} / \mathbf{c m}^{3}\right]$} & {$[\%]$} & {$[\%]$} & {$[\%]$} & {$[\%]$} \\
\hline 1 & 1.84 & 34.1 & 19.2 & 10.1 & nd \\
\hline $2 \mathrm{a}$ & 1.76 & 43.3 & 22.9 & 11.4 & 6.2 \\
\hline $2 \mathrm{~b}$ & 1.76 & 38.4 & 19.5 & 10.0 & 5.6 \\
\hline 3 & 1.59 & 36.8 & 14.7 & 6.4 & 5.3 \\
\hline 4 & 1.44 & 54.0 & 26.5 & 11.7 & 6.3 \\
\hline 5 & 1.26 & 29.0 & 54.0 & 13.0 & nd \\
\hline 6 & 1.18 & 52.0 & 44.5 & 25.2 & 10.5 \\
\hline
\end{tabular}

The decreasing ratio between powder and pellet activity with increasing pellet density thus agreed well with the decreasing effective diffusion coefficient. The very low activity and pellet-powder activity ratio of the high density pellets were thus the result of moderate to strong diffusion limitations. This was also evident when comparing the activation energies measured on the catalyst pellets to those determined on catalyst powder from the crushed pellets (Table 5, Figure S14) and intrinsic activity calculated from the overall effectiveness factors of the catalyst powders and temperature difference over the gas film (Figure S14c, and Section 2.4 for calculation details), as the observed activation energies determined from the pellets were close to half of the intrinsic activation energies $(92-107 \mathrm{~kJ} / \mathrm{mol})$ calculated from the powder measurements (Tables S5-S8).

Table 5: Pre-exponential factors and activation energies calculated by the Arrhenius equation for the pellets and powdered pellets from measurements at $250^{\circ} \mathrm{C}, 300^{\circ} \mathrm{C}, 350^{\circ} \mathrm{C}$ and $400^{\circ} \mathrm{C}$ as well as the pre-exponential factors and activation energies for the intrinsic rate constant determined from the powdered pellets measurements. The intrinsic activity was obtained taking into account the overall effectiveness factor $(\Omega)$ and external heat transfer limitations in the catalyst powder measurements (Tables S5 - S7) giving corrections up to a factor of 2.1.

\begin{tabular}{|c|c|c|c|c|c|c|c|c|}
\hline \multirow{3}{*}{$\#$} & \multirow{3}{*}{$\boldsymbol{\rho}$} & \multicolumn{3}{|c}{ Pellets } & \multicolumn{2}{c|}{ Powder } & \multicolumn{2}{c|}{ Intrinsic } \\
\cline { 2 - 9 } & & $\mathbf{2 5 0 - 4 0 0}^{\circ} \mathbf{C}$ & $\mathbf{3 0 0 - 4 0 0}^{\circ} \mathbf{C}$ & $\mathbf{2 5 0 - 4 0 0}^{\circ} \mathbf{C}$ & \multicolumn{2}{|c|}{$\mathbf{2 5 0 - 4 0 0}^{\circ} \mathbf{C}$} \\
\cline { 2 - 9 } & & $\mathbf{k}_{\mathbf{0}}$ & $\mathbf{E}_{\mathbf{a}}$ & $\mathbf{E}_{\mathbf{a}}$ & $\mathbf{k}_{\mathbf{0}}$ & $\mathbf{E}_{\mathbf{a}}$ & $\mathbf{k}_{\mathbf{0}}$ & $\mathbf{E}_{\mathbf{a}}$ \\
\cline { 2 - 10 } & {$\left[\mathbf{g} / \mathbf{c m}^{3}\right]$} & {$[\mathbf{L} / \mathbf{s} / \mathbf{k g}]$} & {$[\mathbf{k J} / \mathbf{m o l}]$} & {$[\mathbf{k J} / \mathbf{m o l}]$} & {$[\mathbf{L} / \mathbf{s} / \mathbf{k g}]$} & {$[\mathbf{k J} / \mathbf{m o l}]$} & {$[\mathbf{L} / \mathbf{s} / \mathbf{k g}]$} & {$[\mathbf{k J} / \mathbf{m o l}]$} \\
\hline $2 \mathrm{a}$ & 1.76 & $4.18 \cdot 10^{5}$ & 53.7 & 48.9 & $5.88 \cdot 10^{9}$ & 91.9 & $4.29 \cdot 10^{10}$ & 101.0 \\
\hline $2 \mathrm{~b}$ & 1.76 & $2.95 \cdot 10^{5}$ & 52.2 & 49.4 & $4.14 \cdot 10^{9}$ & 89.8 & $3.40 \cdot 10^{10}$ & 99.4 \\
\hline 3 & 1.59 & $2.40 \cdot 10^{5}$ & 50.7 & 48.1 & $1.06 \cdot 10^{10}$ & 93.1 & $5.84 \cdot 10^{10}$ & 101.0 \\
\hline 4 & 1.44 & $1.11 \cdot 10^{6}$ & 55.5 & 47.4 & $5.74 \cdot 10^{10}$ & 100.9 & $2.18 \cdot 10^{11}$ & 107.2 \\
\hline 5 & 1.26 & $3.44 \cdot 10^{6}$ & 58.4 & 46.9 & $1.00 \cdot 10^{10}$ & 89.8 & $1.49 \cdot 10^{10}$ & 92.2 \\
\hline 6 & 1.18 & $1.52 \cdot 10^{7}$ & 65.7 & 51.2 & $4.64 \cdot 10^{10}$ & 99.4 & $1.29 \cdot 10^{11}$ & 104.3 \\
\hline
\end{tabular}


The activation energy increased from about $50 \mathrm{~kJ} / \mathrm{mol}$ to about $65 \mathrm{~kJ} / \mathrm{mol}$ with decreasing pellet density indicating that the difference in porosity changed the kinetic regime from strong internal diffusion limitations at high pellet density to be closer to kinetic control for the less dense pellets. Furthermore, the Arrhenius plot was observed to not fit well for the low density pellets (Figure S14). If omitting the data point at $250^{\circ} \mathrm{C}$ for the calculation of the activation energy, the activation energy becomes very close to $\mathrm{E}_{\mathrm{a}, \text { intrinsic }} / 2$ for all the pellets, indicating that all the pellets become strongly diffusion limited at temperatures above $250{ }^{\circ} \mathrm{C}$. This gave further evidence for the transition of the lighter pellets from a more kinetically controlled regime $\left(\sim 250-300^{\circ} \mathrm{C}\right)$ to a strongly diffusion limited regime at higher temperatures.

The pellet activity was calculated from the intrinsic powder activity and the random pore model for calculating the effectiveness factor (Equations (6)-(8) and (10)-(14)). As can be seen from Figure 7 a satisfactory description of the pellet activity from high to low density pellets at all temperatures was obtained.

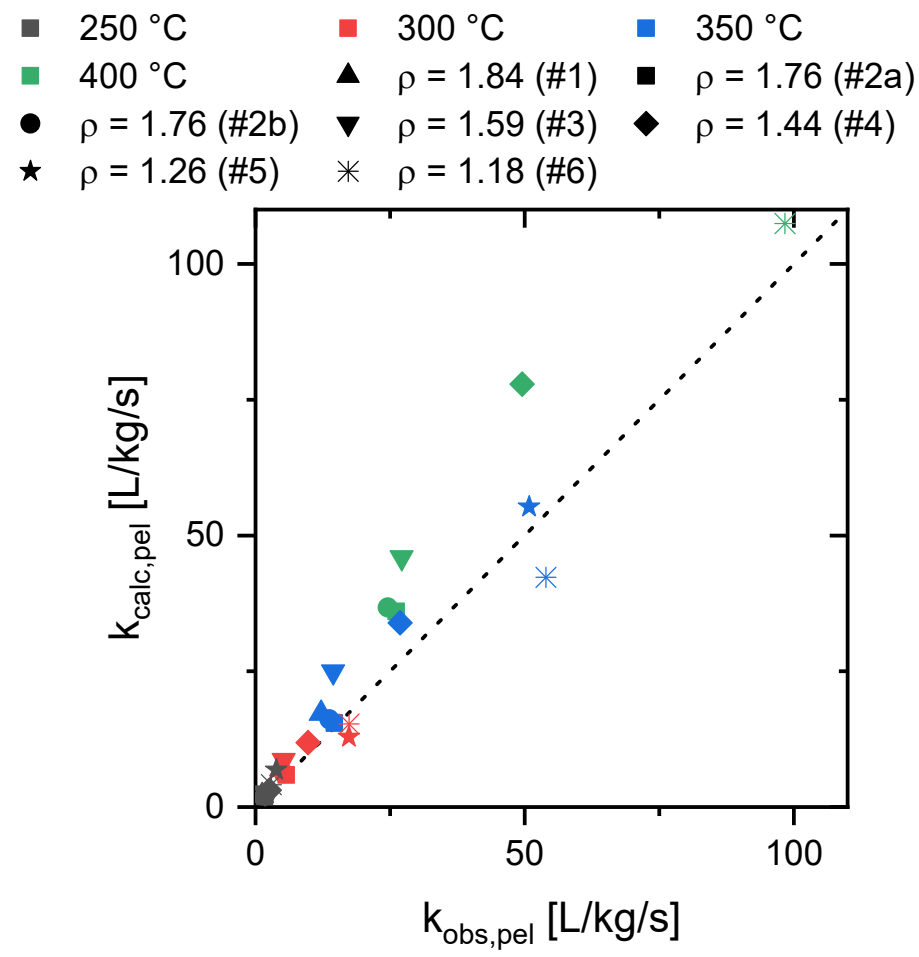

Figure 7: Parity plot for observed and calculated pellet rate constants from the calculated intrinsic rate constants utilizing the random pore model for the effective diffusion coefficient in the overall effectiveness factor for spherical geometry for both powder and pellets, taking into account the temperature differences over the gas film. 
The pellet rate constants were mostly over-predicted by the random pore model using the intrinsic activity calculated from the powder measurements and Hg-porosimetry. This could partly be because the Hg-porosimetry was performed on the support pellets, and not the final impregnated catalysts, which may slightly overestimate the porosity.

Since catalyst stability is the main driver for industry to develop a new Formox catalyst, the catalytic activity and selectivity for the single pellets were measured for $100 \mathrm{~h}$ on stream at $350^{\circ} \mathrm{C}$ (Figure 8 ). The catalysts deactivated only slightly, with the highest loss for the less dense pellets, being similar to the loss in activity for the FeMo catalyst. A slight decrease in the selectivities was also observed (see Figure 8(b)). The Mo/HAP catalysts were 6-13\% points less selective than the FeMo catalyst, and the selectivity also decreased faster than for the FeMo catalyst.

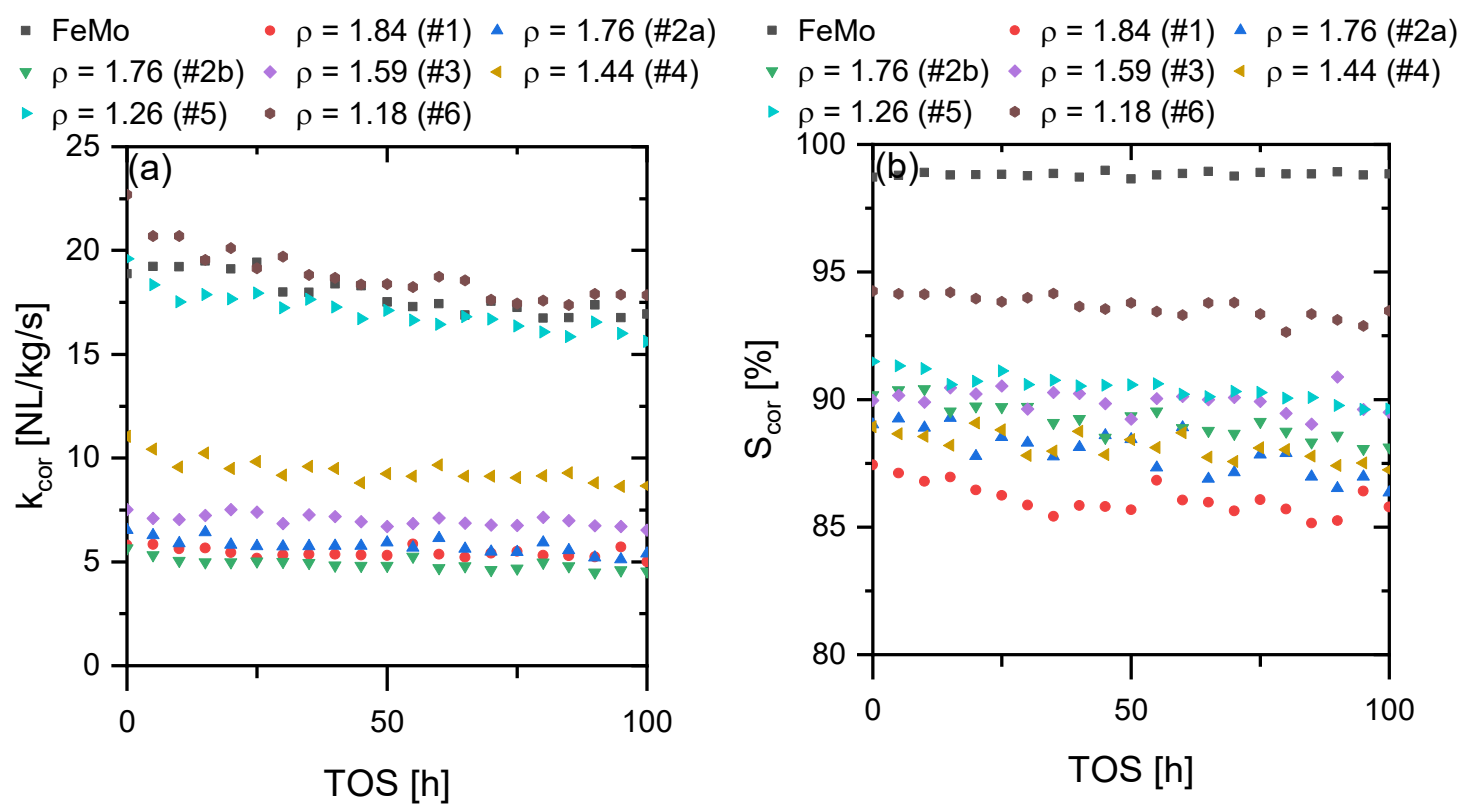

Figure 8: Observed reversible byproduct corrected rate constant (a) and selectivity (b) as function of time on stream for a single pellet for different density pellets at $350^{\circ} \mathrm{C}, 300 \mathrm{NmL} / \mathrm{min}, 5 \mathrm{vol} . \%$ $\mathrm{MeOH}, 10 \mathrm{vol} . \% \mathrm{O}_{2}$ in $\mathrm{N}_{2}$. The carbon mass balance was mostly within $2 \%$ but up to $6 \%$.

The superior catalytic stability observed on the powder $\mathrm{MoO}_{3} / \mathrm{HAP}$ catalysts compared to the powder FeMo catalyst ${ }^{37}$ was thus not observed (Figure 8(a), Figure S15) during the measurements over $100 \mathrm{~h}$ on stream at $350^{\circ} \mathrm{C}$ on single catalyst pellets. The FeMo pellet became slightly more active within the first $10 \mathrm{~h}$ on stream after which it steadily deactivated (Figure S15), whereas the $\mathrm{MoO}_{3} / \mathrm{HAP}$ samples 
deactivated more monotonically. The activity of the pellets decreased at similar rates from $25 \mathrm{~h}$ to 100 $\mathrm{h}$ on stream. A slight decrease in the pellet stability with decreasing pellet density was observed (Figure S15) as the activity loss was $\sim 10 \%, \sim 18 \%, \sim 18 \%, \sim 12 \%, \sim 20 \%, \sim 18 \%, \sim 23 \%$ for decreasing pellet density from $1.84 \mathrm{~g} / \mathrm{cm}^{3}$ to $1.18 \mathrm{~g} / \mathrm{cm}^{3}$.

The most significant change over time in the specific selectivities for the catalysts were in most cases a shift in selectivity between formaldehyde and dimethoxymethane, giving close to no change in the corrected selectivity. The small loss in the corrected selectivity was primarily due to increases in the CO selectivity during time on stream but also selectivities to methyl formate and $\mathrm{CO}_{2}$ increased slightly, though these selectivities were overall very low. For the FeMo pellet, the selectivities towards $\mathrm{CO}, \mathrm{CO}_{2}$ and MF did not have significant changes, whereas the selectivity towards DME doubled and that towards DMM became 4 times the initial value (Figure S16-Figure S23).

\subsection{Discussion}

Comparing the selectivities of the pellets (Figure 6) with the powder selectivities ${ }^{37}$, it is evident that the formaldehyde selectivity is lower for the pellets, both for the FeMo reference and the $10 \mathrm{wt} \%$ $\mathrm{MoO}_{3} / \mathrm{HAP}$ catalysts. The selectivity loss was especially high at high pellet densities. This could be explained from the difference in transport properties and effectiveness factor. This also highlights the significance of the slightly higher over-oxidation activity of the $\mathrm{MoO}_{3} / \mathrm{HAP}$ catalysts compared to the FeMo catalyst in powder form. This property increases when the catalyst is pressed as pellets, due to diffusion limitations for formaldehyde out of the pellets.

Andersson et al. ${ }^{3}$ have previously reported the selectivity towards $\mathrm{CO}$ to decrease with increasing macro pore volume for a FeMo catalyst at $257^{\circ} \mathrm{C}, 6 \% \mathrm{MeOH}$ and $10 \%$ oxygen for conversions of 98 $99 \%$. This is in good agreement with the selectivity results in this study, where a higher formaldehyde selectivity was observed with increased macro pore volume (Figure 8b).

The comparatively high stability of the powder $10 \mathrm{wt} \% \mathrm{MoO}_{3} / \mathrm{HAP}$ relative to the FeMo reference ${ }^{37}$, was not observed for the pellets, and shows the importance of performing studies on relevant sized 
pellets when developing industrial catalysts. The reason for the difference in comparative stability between powder and pellets probably arise from different dominating mechanisms of deactivation. A likely explanation could be that pressing the powder into pellets made the molybdenum transport out of the pellet the limitation on the deactivation rate instead of the rate of volatilization of molybdenum. This can be substantiated by the fact that Mo volatilization from FeMo is significantly transport limited, as all excess $\mathrm{MoO}_{3}$ disappeared within $10 \mathrm{~h}$ on stream for powder measurements ${ }^{23}$, while that was not the case for FeMo pellets after more than $100 \mathrm{~h}$ on stream ${ }^{27}$. More strongly bound Mo may thus give higher stability for powder, but the effect is limited for pellets. However, this make it even more cumbersome to screen for more stable catalysts for the oxidation of methanol to formaldehyde. Alternatively, the research focus should move to engineer optimal porosity instead of new material.

The activity of the \#5 and \#6 pellets were found to be very similar to the FeMo reference catalyst over the period of $100 \mathrm{~h}$ and so the $\mathrm{MoO}_{3}$ volatilization from Figure 2 can be directly compared. From this, the amount of volatilized Mo, which would condense as $\mathrm{MoO}_{3}$ in the void space downstream in the reactor, could be decreased by $76 \%$ by changing from the FeMo catalyst to the $10 \mathrm{wt} \% \mathrm{MoO}_{3} / \mathrm{HAP} \rho$ $=1.26 \mathrm{~g} / \mathrm{cm}^{3}$ (\#5) pellets and by $70 \%$ by changing to the $\rho=1.18 \mathrm{~g} / \mathrm{cm}^{3}$ (\#6) pellets, which had a better selectivity, but such a low mechanical stability that practical application is unlikely. Hence, a significant reduction in pressure drop from $\mathrm{MoO}_{3}$ volatilization can be expected, but with a cost on the formaldehyde selectivity. Exchanging only the inlet part of the catalyst bed might thus yield an optimum case where the selectivity loss is acceptable, while a significant reduction of the pressure drop increase could be achieved.

It is obvious from the results in this work that the porosity and pore-size distribution of the catalyst pellets had a significant impact on the catalytic performance, with increasing selectivity and activity with lower density/increased porosity, at the cost of slightly lower stability. From handling the catalyst pellets, it was found that the best performing pellet in this study (\#6 with $\rho=1.18 \mathrm{~g} / \mathrm{cm}^{3}$ ) had poor mechanical properties and could probably not be loaded into an industrial reactor tube. This would likely not be a problem for the $2^{\text {nd }}$ lightest pellet ( $\# 5$ with $\rho=1.26 \mathrm{~g} / \mathrm{cm}^{3}$ ), which was as stable as the FeMo catalyst in handling, while the heavier pellets were significantly stronger than the FeMo catalyst. 
Actual measurements of the catalyst crush strength, would have to be performed before industrial application, but this was not possible here due to the limited number of pellets available and the uncertainty in this measurement, where preferably ten or more pellets should be measured. Additional ways of ensuring good internal transport properties of the catalyst pellets without compromising the mechanical strength could be of interest. This could possibly be obtained by pelletizing with e.g. small amounts of cellulose or other combustible binders, which could be burned off during the calcination. This method was patented as a preparation route for porous supports in the 60 's ${ }^{90}$ and have recently received some research interest for other processes ${ }^{91}$. This would make it possible to both press the pellets more forcefully, ensuring better mechanical coherence, and achieve high porosity as the cellulose fibers would give macro porosity, though a decrease in stability, compared to the neatly pressed pellets, from the burning of cellulose would have to be expected.

The influence of the pore size on the $\mathrm{MoO}_{3}$ loss was seen from the ICP measurement, by an increase in the Mo loss with increased numbers of macro-pores. This effect is thought to be from two different factors. Firstly, as the effectiveness factor increased, the methanol concentration inside the pellet increased, and the amount of $\mathrm{MoO}_{3}$ becoming volatile thus increased. Secondly, the larger pores which increases the internal diffusion of methanol also increases the diffusion of the volatile Mo-species. Though the exact molecular structure of the evaporating Mo-methoxy species is still not fully known, the effect of small pores on the diffusion of the volatile species out of the pellet is expected to be larger than on methanol and formaldehyde, due to the larger molecule size. Thus, engineering of well-defined macro pores might allow for optimizing the activity and selectivity while minimizing the $\mathrm{MoO}_{3}$ loss.

\section{Conclusion}

$\mathrm{MoO}_{3} / \mathrm{HAP}$ catalyst pellets with different densities and porosities were prepared and investigated for selective oxidation of methanol to formaldehyde. An improvement of the selectivity as well as conversion and activity were obtained by lowering the pellet density from $1.84 \mathrm{~g} / \mathrm{cm}^{3}$ to $1.18 \mathrm{~g} / \mathrm{cm}^{3}$, due to increased porosity, especially macro porosity, significantly improving the effective diffusion inside the catalyst pellets. It was possible to calculate the observed pellet activity from the powder intrinsic activity and the effectiveness factor calculated from the porosity obtained from Hg-porosimetry as input to a 
random pore model for the effective diffusion. The volatilization of $\mathrm{MoO}_{3}$ was found to increase with increasing porosity, indicating that the volatilization process was diffusion limited inside the pellet, resulting from both methanol transport into the pellet and the volatile Mo-methoxy specie transport out of the pellet. Advantageously, the loss of Mo was much smaller for the HAP supported catalysts compared to that for the FeMo reference catalyst, and a decrease of the Mo loss of over $70 \%$ could be achieved by changing to the $10 \mathrm{wt} \% \mathrm{MoO}_{3} / \mathrm{HAP}$ catalyst. The most active and selective pellet was the $10 \mathrm{wt} \% \mathrm{MoO}_{3} / \mathrm{HAP}\left(\rho=1.18 \mathrm{~g} / \mathrm{cm}^{3}\right.$, \#6) pellet, which however had the lowest mechanical strength. It achieved a corrected selectivity to formaldehyde of $94.2 \%$ at $23.8 \%$ conversion at $350^{\circ} \mathrm{C}$. The selectivity to the main over-oxidation product $\mathrm{CO}$ was $4.7 \%$. No significant differences in catalytic stability were observed within $100 \mathrm{~h}$ on stream at $350^{\circ} \mathrm{C}$, when comparing a FeMo reference catalyst and the 10 $\mathrm{wt} \% \mathrm{MoO}_{3} / \mathrm{HAP}$ catalyst pellets with different density. Despite the $\mathrm{MoO}_{3} / \mathrm{HAP}$ catalysts did not outperform the FeMo reference, further optimization of the catalyst synthesis and pellet formulation may improve it and make it industrially relevant, as the difference was not large. The results highlight the importance of performing catalyst development on industrially relevant pellet sizes.

\section{Conflicts of Interest}

There are no conflicts of interests to declare.

\section{Acknowledgement}

This study was part of a collaboration between the CHEC research center at Department of Chemical and Biochemical Engineering at DTU and Haldor Topsøe A/S. Funding from the Independent Research Fund Denmark (DFF - 4184-00336) is gratefully acknowledged. Help by Ulrich Ebbehøj Fjeldsted (Pelletizing), Caroline Piper Hem (XRD), Eva Charlotte Bendixen (SEM), and other technical staff at Haldor Topsøe A/S with the characterization is gratefully acknowledged.

\section{References}

1 Cision, Global Formaldehyde Market 2018-2022, https://www.prnewswire.com/newsreleases/global-formaldehyde-market-2018-2022-300633054.html, (accessed 25 April 2019).

2 Merchant Research \& Consulting 1td, Formaldehyde: 2020 World Market Outlook and Forecast up to 2029, https://mcgroup.co.uk/researches/formaldehyde, (accessed 21 July 2020).

3 A. Andersson, J. Holmberg and R. Häggblad, Top. Catal., 2016, 59, 1589-1599. 

and A. Hilt, Ullmann's Encycl. Ind. Chem., 2016, 1-34.

H. R. Gerberich, G. C. Seaman and Hoechst-Celanese Corporation, in Kirk-Othmer Encyclopedia of Chemical Technology, John Wiley \& Sons, Inc., 2013, pp. 24-26. L.-O. Andersson, Informally Speak. A formaldehyde Mag. from Johnson Mathey, 2019, 12-13. K. Routray, W. Zhou, C. J. Kiely, W. Grünert and I. E. Wachs, J. Catal., 2010, 275, 84-98. E. Söderhjelm, M. P. House, N. Cruise, J. Holmberg, M. Bowker, J.-O. Bovin and A. Andersson, Top. Catal., 2008, 50, 145-155.

M. Bowker, C. Brookes, A. F. Carley, M. P. House, M. Kosif, G. Sankar, I. Wawata, P. P. Wells and P. Yaseneva, Phys. Chem. Chem. Phys., 2013, 15, 12056-12067.

11 C. Brookes, P. P. Wells, G. Cibin, N. Dimitratos, W. Jones, D. J. Morgan and M. Bowker, ACS Catal., 2014, 4, 243-250.

12 C. Brookes, P. P. Wells, N. Dimitratos, W. Jones, E. K. Gibson, D. J. Morgan, G. Cibin, C. Nicklin, D. Mora-Fonz, D. O. Scanlon, C. R. A. Catlow and M. Bowker, J. Phys. Chem. C, 2014, 118, 26155-26161.

13 C. Brookes, M. Bowker, E. K. Gibson, D. Gianolio, K. M. H. Mohammed, S. Parry, S. M. Rogers, I. P. Silverwood and P. P. Wells, Catal. Sci. Technol., 2016, 6, 722-730.

14 L. J. Burcham, L. E. Briand and I. E. Wachs, Langmuir, 2001, 17, 6164-6174.

15 A. Andersson, M. Hernelind and O. Augustsson, Catal. Today, 2006, 112, 40-44.

16 K. I. Ivanov and D. Y. Dimitrov, Catal. Today, 2010, 154, 250-255.

17 B. I. Popov, V. N. Bibin and G. K. Boreskov, Kinet. i Katal., 1976, 17, 371-377.

18 A. M. Beale, S. D. M. Jacques, E. Sacaliuc-Parvalescu, M. G. O’Brien, P. Barnes and B. M. Weckhuysen, Appl. Catal. A Gen., 2009, 363, 143-152.

19 A. P. V. Soares, M. F. Portela, A. Kiennemann, A. P. Vieira Soares, M. Farinha Portela, A. Kiennemann, A. P. V. Soares, M. F. Portela and A. Kiennemann, Catal. Rev. Sci. Eng., 2005, 47, 125-174.

20 A. P. V. Soares, M. F. Portela, A. Kiennemann and L. Hilaire, Chem. Eng. Sci., 2003, 58, $1315-1322$.

21 B. I. Popov and N. G. Skomorokhova, React. Kinet. Catal. Lett., 1982, 18, 101-105.

22 N. Burriesci, F. Garbassi, M. Petrera, G. Petrini and N. Pernicone, Stud. Surf. Sci. Catal., 1980, 6, 115-126.

23 K. V. Raun, L. F. Lundegaard, J. Chevallier, P. Beato, C. C. Appel, K. Nielsen, M. Thorhauge, A. D. Jensen and M. Høj, Catal. Sci. Technol., 2018, 8, 4626-4637.

24 A. Gaur, M. Schumann, K. V. Raun, M. Stehle, P. Beato, A. D. Jensen, J.-D. Grunwaldt and M. Нøj, Chem CatChem, 2019, 11, 4871-4883.

25 A. Gaur, M. Stehle, K. V. Raun, J. Thrane, A. D. Jensen, J.-D. Grunwaldt and M. Høj, Phys. Chem. Chem. Phys., 2020, 22, 11713-11723.

26 K. V. Raun, M. Thorhauge, M. Høj and A. D. Jensen, Chem. Eng. Sci., 2019, 202, 347-356.

27 K. V. Raun, J. Johannessen, K. McCormack, C. C. Appel, S. Baier, M. Thorhauge, M. Høj and 
A. D. Jensen, Chem. Eng. J., 2019, 361, 1285-1295.

M. H. Peyrovi, N. Parsafard and H. Hasanpour, Bull. Chem. React. Eng. Catal., 2018, 13, 520.

C. G. Braz, A. Mendes, J. Rocha, R. Alvim and H. A. Matos, Chem. Eng. Sci., 2019, 195, $347-355$.

30 S. Chapman, C. Brookes, M. Bowker, E. K. Gibson and P. P. Wells, Faraday Discuss., 2016, 188, 115-129.

31 N. V. Nikolenko, I. V. Kozhevnikov, A. O. Kostyniuk, H. Bayahia and Y. V. Kalashnykov, J. Saudi Chem. Soc., 2018, 22, 372-379.

T. Choksi and J. Greeley, ACS Catal., 2016, 6, 7260-7277.

33 B. R. Yeo, G. J. F. Pudge, K. G. Bugler, A. V. Rushby, S. Kondrat, J. Bartley, S. Golunski, S. H. Taylor, E. Gibson, P. P. Wells, C. Brookes, M. Bowker and G. J. Hutchings, Surf. Sci., 2016, 648, 163-169.

34 A. P. S. Dias, F. Montemor, M. F. Portela and A. Kiennemann, J. Mol. Catal. A Chem., 2015, 397, 93-98.

B. Partopour and A. G. Dixon, AIChE J., 2019, 1-13.

36 J. Thrane, L. F. Lundegaard, P. Beato, U. V. Mentzel, M. Thorhauge, A. D. Jensen and M. Høj, Catalysts, 2020, 10, 82.

37 J. Thrane, C. F. Elvebakken, M. Juelsholt, T. L. Christiansen, K. M. Ø. Jensen, L. P. Hansen, L. F. Lundegaard, U. V. Mentzel, M. Thorhauge, A. D. Jensen and M. Høj, .

H. Inokawa, S. Zaman, H. Driss, M. Daous and A. Al-zahrani, in EUROPA CAT, 2017.

F. A. Chernyshkova, Pet. Chem., 1991, 31, 571-584.

R. Castillo, K. Dewaele, P. Ruiz and B. Delmon, Appl. Catal. A Gen., 1997, 153, L1-L8.

B. Ramachandra, J. S. Choi, K. Y. Choo, J. S. Sung, S. D. Song and T. H. Kim, Catal. Letters, $2005, \mathbf{1 0 5}, 23-27$.

42 N. G. Valente, L. A. Arrúa and L. E. Cadús, Appl. Catal. A Gen., 2001, 205, 201-214.

43 R. S. Mann and R. A. Diaz-Real, in Proceedings of the 10th International Congress on Catalysis, Budapest, 1993, pp. 1991-1994.

44 A. Kostynyuk and M. Nikolenko, Chem. Chem. Technol., 2011, 5, 89-93.

45 Y. Matsuoka, M. Niwa and Y. Murakami, J. Phys. Chem., 1990, 94, 1477-1482.

46 L. J. Burcham, M. Badlani and I. E. Wachs, J. Catal., 2001, 203, 104-121.

47 N. Arora, G. Deo, I. E. Wachs and A. M. Hirt, J. Catal., 1996, 159, 1-13.

48 T. Kropp and J. Paier, J. Phys. Chem. C, 2015, 119, 23021-23031.

49 P. Hellier, P. P. Wells and M. Bowker, Chinese J. Catal., 2019, 40, 1686-1692.

50 J.-M. Jehng, H. Hu, X. Gao and I. E. Wachs, Catal. Today, 1996, 28, 335-350.

51 Y. Chen and I. E. Wachs, J. Catal., 2003, 217, 468-477.

52 I. E. Wachs, G. Deo, H. Hu, N. Arora and J.-M. Jehng, Catal. Today, 1996, 28, 199-205.

53 S. A. El-Molla and H. R. Mahmoud, Mater. Res. Bull., 2013, 48, 4105-4111.

54 M. Massa, R. Häggblad and A. Andersson, Top. Catal., 2011, 54, 685-697. 
P. Salagre and J. E. Sueiras, J. Chem. Soc. Chem. Commun., 1988, 1084-1085.

D. Klissurski, N. Abadzhieva, S. Kassabov, P. Stefanov, D. Kovacheva and I. Uzunov, Comptes Rendus L'Academie Bulg. des Sci., 2009, 62, 1073-1078.

K. Routray, W. Zhou, C. J. Kiely and I. E. Wachs, ACS Catal., 2011, 1, 54-66. Gen., 2014, 485, 51-57.

G. C. Behera and K. Parida, Chem. Eng. J., 2012, 180, 270-276. Hutchings and J. K. Bartley, Catal. Sci. Technol., 2013, 3, 1558-1564. 1987, 29, 211-218.

68 G. V. Isaguliants and I. P. Belomestnykh, Catal. Today, 2005, 100, 441-445.

T. Kropp, J. Paier and J. Sauer, J. Catal., 2017, 352, 382-387. Bukhtiyarov, Kinet. Catal., 2016, 57, 82-94.

D. Klissurski and Y. Pesheva, React. Kinet. Catal. Lett., 1986, 32, 77-82.

74 L. Makedonski, V. Nikolov, A. Anastasov and M. Stancheva, React. Kinet. Catal. Lett., 2004, 81, 21-25.

B. M. Reddy, Acs Symp. Ser., 1993, 523, 204-216.

78 G. A. Tsigdinos, H. Y. Chen and B. J. Streusand, Ind. Eng. Chem. Prod. Res. Dev., 1981, 20, 619-623.

79 F. Karlsruhe, Inorganic Crystal Structure Database ICSD, https://icsd.fizkarlsruhe.de/search/basic.xhtml;jsessionid=83E66C26C80F40E7E12A0DAEC8C8C6AD, (accessed 14 August 2019).

80 M. Høj, T. Kessler, P. Beato, A. D. Jensen and J. D. Grunwaldt, Appl. Catal. A Gen., 2014, 472, 29-38.

81 M. Høj, A. D. Jensen and J.-D. Grunwaldt, Appl. Catal. A Gen., 2013, 451, 207-215.

82 K. T. Cheshkova, V. . N. Bibin and B. I. Popov, React. Kinet. Catal. Lett., 1976, 4, 307-313. 
83 R. S. Mann and K. W. Hahn, J. Catal., 1969, 15, 329-341.

84 R. S. Mann and M. K. Dosi, J. Catal., 1973, 28, 282-288.

85 S. A. R. K. Deshmukh, M. van Sint Annaland and J. A. M. Kuipers, Appl. Catal. A Gen., 2005, 289, 240-255.

86 S. K. Bhattacharyya, K. Janakiram and N. D. Ganguly, J. Catal., 1967, 18, 128-136.

87 H. S. Fogler, Elements of Chemical Reaction Engineering, Prentice Hall, Upper Saddle River, NJ, USA, 5th edn., 2016.

88 J. Szekely, J. W. Evans and H. Y. Sohn, Gas-Solid Reactions, Academic Press, New York, United Kin., 1976.

89 G. F. Froment and K. B. Bischoff, Chemical Reactor Analysis and Design, Wiley, 2nd edn., 1990.

90 B. W. Burbidge and P. T. White, UNITED STATES PATENT OFFICE, US 3162607, 1962.

91 P. S. Dhillon, M. P. Harold, D. Wang, A. Kumar and S. Y. Joshi, Chem. Eng. J., 2019, 377, 119734. 